\title{
La diabetes sacarina y su tratamiento dietético
}

\author{
Por CARLOS F. KRUMDIECK
}

\section{CONSIDERACIONES HISTORICAS}

El conocimiento de la diabetes es muy antiguo. Celso 30 años antes de la era Cristiana, llama la a tención sobre una anomalía de la secreción urinaria que se caracteriza por un aumento considerable de la cantidad de orina. ARETEo a fines del II siglo (después de J. C.) describe con mayor precisión la enfermedad y la designa con el nombre de diabetes (atravezar), creyendo que los riñones atraian las bebidas y las eliminaban sin que sufriesen transformación alguna.

En los manuscritos de los médicos árabes e indios del siglo VII, se encuentra también descrita la enfermedad, y esos médicos apuntan ya el sabor melífuo de las orinas diabéticas.

Teophrasto von HoHenheim, más conocido con el nombre de Paracelso, a principios del siglo XVI fué el primer médico de Europa que llamó la atención sobre una alte. ración de la sangre, que determinaba una excitación de la función renal, caracterizada por el aumento inmoderado de la cantidad de orina.

A fines del siglo XII, el médico inglés Tomás Wiluis, hizo notar el becho de que la orina diabética, tiene un sábor tan dulce como si estuvierá mezclada con azúcar o miel. No atribuía este sabor dulzaino a la presencia de azúcar, sino que creía que aquel se debía a termentaciones especiales de la orina que enmascaraban su sabor natural.

Fué necesario que trascurriera un siglo más para que se demostrara que el sabor melífluo de la orina diabética se debia al azficar. Este honor corresponde también a Inglaterra, 
pues fué Mateo Dobson quien en el año de 1773 , constát 6 quimicamente la presencia de azúcar en la orina de los diabéticos.

Cuatro años más tarde, en 1777, aparece la primera monografia de Rollo en la que explica el mecanismo de la glucosuria por un trastorno de la digestión y de la asimilación, en virtud del cual mediante el mal quimismo alimenticio, pasa a la sangre y a los tejidos una cantidad exagerada de azúcar, la que es eliminada por los riñones.

De acuerdo con su doctrina patogénica, Rollo dictó las primeras bases de la dietética de los diabéticos, proscribiendo de su régimen alimenticio toda clase de alimentos azucarados y farináceos y recomendándoles la dieta a nimal exclusiva.

Nicolas y Gueudeville el año de 1803, reafirman el origen digestivo de la diabetes, pero sosteniendo que la glucosuria era debida a la falta de asimilación del nitrógeno, lo que impedía la fijación en los tejidos de los principios nutritivos, y quedando en libertad el carbono, hidrógeno y oxígeno, estos se combinarían para formar azucar.

Ambrosini en 1815 demuestra que el aźicar no es un -elemento extraño en la economía. sino que existe normalmente en la sangre. Poco tiempo después Magendif rátifica - el deseubrimiento que de la glucemia había hecho Ambrosi: NI y agrega que el aźricar de la sangre, se forma a expensas ،del almidón.

En poseción de áquel dato, cuya impotancia se reafirma con los descubrimientos de la hora actual, Bouchardat en 1839, establece que las glucosurias son debidas a un aumento de la taza normal del azúcar sanguínea. Esta hiperglucemia se podría deber: $1^{\supset}$ a una abundante producción de aźa. car por trastornos del aparato digestiro que acarrearía una transformación más rápida del almidón en glucosa, la que pasando a la sangre aumentáría su tenor; $y, 2^{\circ}$ a una insuficiente destrucción de aźicar por los tejidos, hecho que traería consigo la acumulación de aquella en la sangre. Con mucha frecuencia, ambos fenómenos coexistirian en un mismo individuo.

Hasta eutonces, como se ve, todas las doctrinas patogénicas tendian a considerar la diabetes como debida a trastornos digestivos.

Von Stosh, en 1828 admite hipotéticamente que la diabetes podía ser de origen cerebral. 
En 1848 Cla udo Bernakd produce la glucosuria por su célebre picadura del suelo del cuarto ventrículo. Sugestio. nados por el demostrativo experimento de BERNARD, los investigadores pensaron que las irritaciones permanentes del sistema nervioso podrian determinar diabetes crónicas. Se encontraban apoyados, además, por la frecuencia de la diabetes en los neurasténicos y psicasténicos.

Claudio Bernard, en una serie de investigaciones lleva. das a cabo en el decenio de 1848 a 1858 , demuestra: que el organismo animal puede fabricar azticar a expensas de las proteínas; que es el hígado el encargado de esa funcion, la que está controladá por el sistema nerviosc. En ese mismo período, áisla el glicógeno. En una palabra, había descubierto la glucogenia hepática.

Los clínicos, recogiendo las enseñanzás de lá fisiología, comienzan a abandonar las doctrinas que atribuyen a trastornos digestivos la patogenia de la diabetes y tratan de explicarla por perturbaciones de la glicogenia hepática.

Foster y Dickinson fueron los primeros en átribuir una de las formas de la diabetes a una exageración de la glicogenia hepática, debida a excitaciones de las ramificaciones intrahepáticas del neumogástrico.

PaYY en 1860 emite la hipótesis de que el glicógeno hepático se debe normalmente transformar en grasa en el hígado. En los diabéticos pasaría sin transformación a la sangre, donde, bajo la acción de un fermento especial daría nacimiento a la glucosa.

Schiff en 1865 atribuye la diábetes a una perturbación de la crasis sanguínea en virtud de la cual se produciría una fermentación anormal del gliçgeno y la transformación inmediat a de éste en glucosa.

Bence Jones cree que el azucar de la economía no desaparece por oxidación, sino por fermentación; en la diabetes habria alteración de la materia fermentante y por consiguiente este fenómeno no se realizaría bien, cargándose entonces el organismo de glucosa.

ZiEGEL (1871) cree que el fermento que transforma el glucógeno en glucosa está dentro de los glóbulos. En la diabetes habría una destrucción globular más rápida, lo que suministraría al hígado mayor cantidad de fermento capaz de transformar el glicógeno.

Schulzen (1872) piensa que la glucosa por la acción de un termento especial se descompone en el organismo en gli. 
cerina y aldehido glicérico, cuerpos ambos que van a servir al organismo para la oxidación y asimilación. En la diabetes no existiría ese fermento, lo que traería como consecuen. cia la falta de transformación de la glucosa, su paso a la sangre en cautidad mayor de lo normal y su eliminación por la orina.

El año 1867 Petenkoffer y Volt demuestran que en los diabéticos los cambios gaseosos se caracterizan por una menor fijación del oxígeno por los hematies y por una menor excreción de antidrido carbónico; además, las materias proteicas se destruyen más fácilmente que en el individuo sano, siendo su oxidación incompleta por falta de oxígeno. La grasa de los tejidos se formaría por la desasimilación de los albuminoideos en presencia del oxigeno; estando disminuída la cantidad de oxígeno asimilado, no podría formarse grasa y esta sería reemplazada en los tejidos por una sustancia más pobre en oxígeno, esto es: la glucosa.

Miahle por el año 1854 lanza la idea de que la glucasuria en los diabéticos se debe a la falta de combustión de los azficares por el organismo enfermo, y este retardo de la oxidación se debería a su vez, a una defieiente alcalinidad de la sangre. Desde entonces se preconiza el bicarbonato de soda en los diabéticos. Si la teoría de Mia HLE fué errónea, tuvo el merito de haber introducido an recurso terapéutico de positivo valor en muchos casos de diabetes.

Reinoso en 1855 , estudiándo los cambios gaseosos en los diabéticos, pensó que l'a diabetes podría deberse a la insufiente combustión del azlicar, por perturbación de la tunción respicatoria.

EBSTEIN en 1878, teniendo en cuenta la acción inhibito. ria que ejerce el anhidrido, carbónico sobre los fermentos sa. cárificantes y la disminución que del anhidrido carbónico existe en. los diabéticos, desarrolla una teoría seg an la cual, la acción de los fermentos y la glucogenia estarían favorecidos por la lentitud de formación del anhidrido carbónico.

BUChard el año 1877 , considera la diabetes sacarina como urat eufermedad general de lá nutrición, caracterizada primitiva y esencialmente por defecto. 0 insuficiencia de los actos de asimilación, y en particular por falta de consumo del azúcar por los elementos a natómicos.

CaWley en ese mismo año hizo notar por primera vez las relaciones existentes entre la diabetes y las. lesiones del pancreas. Bouchard había ya señalado desde 1846 las fre- 
cuentes lesiones del páncréas e insistia en qué los investigadores profundizasen sus estudios sobre el páncreas de los diabéticos. LaNCEREA ox en 1877 es el primero en individualizar una forma clíuica de diabetes pancrética.

Von Mehring y Minkowsky en 1889, producen experimentalmente la diabetes en los animales de laboratorio, por extirpación completr del pancreas. Lepine y BarraL, basados en esos experimentos, lanzan una nueva doctrina patogénica, según la cual el páncreas tendría una secreción interna cuyo objeto sería transformar el aźrcar de la sangre. En otros términos, para Lepine y BarraL, el pancreas produciria un fermento glucolítico. En los diabéticos habría una menor produccion de dicho fermento.

Pocos años más tarde Chaveau y Kauffuan afirman una idea opuesta a la de Leprne. Para ellos, la secreción interna del páncreas tendría una acción inhibitoria sobre la glucogenia hepatica. En la diabetes habría un aumento de la producción de glucosa, debido a una deficiente frenación del páncreas sobrc la función glicogénica del hígado.

En 1906 NaUnyu define su opinión sobre la diabetes. Para él, la diabetes es una diátesis especial, caracterizada por una debilitación del metabolismo, que se manifiesta por la mala utilización de los hidratos de carbono; esta diátesis se hace más ostensible en caso de lesiones o enfermedades de ciertos órganos, particularmente el páncreas. Además, la herencia y los malos hábitos alimenticios desempeñarian un gran papel en el desárrollo de la enfermedad.

Alten en 1914, después de pacientes investigaciones anatomo-patológicas $y$ de estudios llevados a cabo en animales, bechos experimentalmente diabéticos, llega a la conclusion de que la diabetes es una enfermedad que se debe a un debilitamiento de la función endocrínica del páncreas. Segan el, lo's islotes de LANGERHANs suministran al organismo una sustancia que obrando a manera de sensibilizatriz, fija en forma especial la glucosa. Eu los diabéticos, falta ese amboceptor, lo que trae como consecuencia que la glucosa pase directamente a lá sangre.

VoN Noorden en 1917, sostiene una doctrina enteramente análoga, según la cual la diabetes es una consecuen. cia necesaria de una insuficiencia del sístema de islotes del páncreas, por una debilitación o supresión de la acción 
específica imprescindible de aquel sobre la regulación des azficar.

Los resultados obtenidos Gltimamente en el departamento de fisiología de la Universidad de Toronto que han. culminado en el descubrimiento de la insulina por BANTING, Best y MACLEOD, agregan un argumento más en favor de las concepciones de Allen y Noorden.

Marcelo labBé en 1920, no vé en la diabetes una entidad mórbida, sino un sindrome debido a un trastorno del a parato glicoregulador.

Por fltimo el año 1921, Agurlar Meza de Honduras, ha emitido la hipótesis de que la diabetes es producida por una autointoxicación de origen endocrínico, presentando todo diabético lesiones crónicas o pasajeras de alguna glán. dula de secreción interna.

En la literatura médica nacional, solo se registra en lo. que a diabetes se refiere, dos lecciones clínicas del profesor Odriozola, una de ellas muy interesante, sobre la "Cura de Alren". El capítulo que sobre acción Bramotológica,. consigna el protesor Manrique en su programa de Terapéuca y Materia Medica, y un artículo del profesor Monfe, de reciente publicación sobre la diabetes y su tratamientopor el método de Josi.in.

\section{Etiología de la Diabetes}

Las causas de la diabetes sacarina, son múltiples y variadas. Pasaré suscintamente en revista, todas las circunstancias que predisponen a la eclosión de la enfermedad, así. como también algunos otros estádos mórbidos, que en veces, son causa determinante de la diabetes.

Obesidad.-Para Josin, en el 40 por ciento de los casos sobre una estádística de más de 900 enfermos, figura la obesidad como predecesora de la drabetes. Ya desde antiguo se conocia la fiecuencia de lá diabetes en los obesos. No es raro hallar en los antecedentes de las personas atacadas de diabetes sacarina, el dato de obesidad seguida de enflaquecimiento y pérdida de peso. Así como también es muy frecuente la obesidad entre los antecedentes familiares. de los entermos. 
Excesos alimenticios.-Otro factor importante es la ingestión inmolerada de alimentos; hecho que por sí sólo no basta para ocasionar la diabetes, pero que en un terreno predispuesto por taras orgánicas o por la herencia, puede ser causa determinante de la aparicion de aquella. Jos LIN anota además que, cuando el consumo de azúcar en los Estados Unidos aumentó en un 17 por ciento en los años de 1900 a 1917 , la mortalidad por diabetes fué doble.

Herencia.-Es este un factor que no debe nunca perderse de vista, Los hijus de los diabéticos, heredan la predisposición, sumánuose a esta desventaja los malos bábitos higiénicos y alimenticios del hogar en que nacieron.

Sedentaridad.-Juega también un papel importante entre las causas que favorecen la eclosión de la diabetes, la vidá demasiado sedentaria en gente con holgura económica y que no verifica la vida activa y de trabajo de las clases populares. Se añade a este hecho la alimentación excesiva y regalada que les permite su fortuna. Asi se explica la rareza de casos de diabetes en nuestra población hospitalaria, constituída en su mayor parte por obreros y carapesinos.

Edad y sexo.-La diabetes puede estallar en cualquier edad de la vida, pero es más frecuente entre los 40 y 60 ã̃os. Bouchardat fué el primero en señalar que la diabetes es tanto más grave cuanto más joven es la persona atacada. En cuanto al sexo, todos los autores señalan una mayor frecuencia en el sexo masculino. En la mujer es bastante frecuente que las primeras manifestaciones se presenten ell la época de la menopausia.

Infuencias netviosas.-Desde Claudro BernaRd, se conoce la importancia que juega el sistema nervioso en la glucosuria. Cualquier tumor que comprima el cuarto ventrículo puede determinar una glucosuria persistente. Los traumatismos craneanos pueden muchas veces originarlas también, pero, es presumible que en estos casos, pequeñas hemorragias colectádás en el suelo del cuarto ventriculo actún por un mecanismo análogo al de la punción de Claudio Bernard. También se ha señalado la presencia del azúcar en la orina de los alienados, particularmente en la de los melancólicos, neurasténicos e histéricos. Una 
excitación psíquica fuerte es capaz en muchos casos de pro. -ducir esa eliminacion. En Estados Unidos se ha comproba. do la presencia de azúcar en la orina de buen numero de individuos que iban a sufrir las pruebas del examen escolar. VON NOORDEN ha señalado la aparición de numerosos casos de diabetes, durante la gran guerra, en las filas del ejercito alemán. A primera vista podría incriminarse al traumatis. mo psíquico del combate este aumento de diabéticos, pero el mismo investigador deja constancia que la mayoría de esos enfermos, por sus antecedentes personales o familiares, pod́án haber sido calificados como diabéticos latentes $y$ Ja excitación nerviosa que experimentaron duraute sus servicios en la guerra, fué simple pretexto para la eclosion de una enfermedad que siempre se hubiese manifestado.

Traumatismos.-Se ha constatado también la aparicion de glucosa en la orina, a consecuencia de traumatismos extensos, especialmente en las fracturas. La hiperglicemia se presenta en casi el 100 por ciento de los casos de traumatismos importantes; pudiendo ser estos el punto inicial de la diabetes en individuos predispuestos por la herencia o por malos hábitos higiénicos.

Infecciones. - Se ha tratado de incriminar a distintas enfermedades infecciosas agudas, la causa de la diabetes, pero esto no ha podido demostrarse, no obstante, ello sería comprensible en aquellas entermedaldes que pueden alterar el fisiologismodel sistema insular del páncreas, más aún si éste presentaba ya un ligero hipofuncionalismo.

Sífilis.-Fourner pensó que la diabetes estaba destinada a entrar en el grupo de las afecciones parasifíticas y decía: "Se le encuentra demasiado frecuentemente en rela. "ción con la síflis, para que no haya entre ellas un cierto "lazo patogénico". Autores franceses, Marcelo Pinard y Velcuot, entre otros, afrman la etiología sifilítica de la diabetes, basándose no solo en sus estadísticas personales y los resultados del tratamiento antisifíítico, feliz en mu. chos casos de diabetes, sino también y sobre todo en la similiturl que hay entre las complicaciones nerviosas de la diabetes y la neurosifllis. Este mismo factor sifítico, con su contagiosidad explicaría los frecuentes casos de diabetes conyugal y familiar. Josin, no atribuye papel etiológico 
a la sifilis en la diabetes y su estadistica de diabéticos es pobre en sifilíticos.

Tuberculosis.-Frecuentemente se olserva la asociación de la tuberculosis con la diabetes, sobre todo en los jóvenes, revistiendo en estos una gravedad inusitada por agregarse a la desnutricion propia de la diabetes la de la tuberculosis. La tuberculosis del páncreas, es también aná crusá de diabetes.

Arterioesclerosis.-De todas las enfermedades que se asocian conlid diabetes, es sin duda la arterioesclerosis, la que mayormente se presenta, hábiéndose querido hacer depender acluella de ésta. Ambas se observan en las personas que tienen retardo de la nutrición y que cometen excesos en los alimentos y bebidas. Teniendo condiciones etiológicas semejantes es muy posible, que coexistan en el mismo individuo sin ser una la causa de la otra, pero que asociadas ensombrecen recíprocamente el pronóstico de los enfermos, por prestarse mutuo a poyo.

Puede decirse lo mismo de la asociación de la diabetes con la gota y con muchas otras enfermedades, sin que se haya podido demostrar entre ellas relaciones de causalidad.

El doctor Monge llama la atención en su curso de Patología Interna sobre la frecuencia de las hemorragias cerebrales de los diabeticos, y que el atribuye a perturbaciones metabólicas que irian a reflejarse sobre los endotelios vasculares y cuya traducción sería la lipenia y la hiperco. lesterinemia.

\section{Fisiopatología}

Conocidas ya las distintas doctrinas patogénicas y las condiciones etiológicas que determinan la diabetes sacarina, voy a ocuparme del mecauismo fisiopatológ:co de la enfermedad, para de ahí deducir las indicaciones terapéuticas que se deben cumplir.

El sintoma cardinal y constante de la diabetes, es la glucosuria. Pero la glucosuria no es utra cosa que la consecuenciá del aumento de la glurosa circulante; quiere decir, que es la traducción de la hiperglicemia. Estando aumentado el tenor de glucosa en la sangre y permaneciendo fijo 
el dintel o nivel ( (seuiln de los franceses) de la eliminación renal, aquella deberá fatalmente pasar a la orina, reclamando para poder ser eliminada, cierta cantidad de agua en relación más o menos estrecha con la cantidad de azúcar que debe ser expulsada, lo que explica otro de los sintomas: la poliuria.

Habiendo hiperglicemia, existe hiperglicistia, y esta im. pregnación de los tejidos por el aźcar reclama también para su disolución agua, que los enfermos tratan incesantemente de beber para satisfacer la intensa sed de que son víctimas (polidipsia). Además, elimiminándose por la orina fuertes cantidades de glucosa, acetona, etc., pierden igualmente fuertes valores energéticos, que el organismo trata de reponer aumentando la ración alimenticia (polifagia).

Hay una forma de diabetes, la diabetes renal, en la que la glucosuria se produce sin que haya hiperglicemia, lo que se debe a la baja del "seuil» renal para la glucosa. En estas condiciones, debiendo permanecer fija la cantidad de azficar circulante y bajando el dintel de la eliminación, la glucosuria siempre se presentará, no ya por trastorno metábólico, sino por lesión renal. Hechá esta salvedad, puede establecerse como principio fundamental, que la glucosuria en la diabetes sacarina es debicla siempre a un aumento de lá gliceinia normal.

Antes de establecer el mecanismo de la hiperglicemia, es conveniente conocer cual es el origen y cual el destino de la glucosá en la economía.

La glucosa proviene de la alimentación; todos los alimentos son capaces de suministrarla, pero son los carbohidratos su principal fuente de formación.

El hombre los toma en los alimentos bajo la forma de mono, di ó polisacáridos; todos ellos bajo la acción de los jugos digestivos, son transformados en monosacá ridos. La sacar rosa, por ejemplo, bajo la acción de la invertina del jugo intestinal, se desdobla en glucosa y levulosa; el almidón, después de pasar por una serie de cuerpos intermediarios, es totalmente transformado en glucosa, etc.

Bajo la forma de glucosa, los alimentos hidrocarbonados son absorbidos en su totalidad por las vellosidades intestinales, para luego pasar al hígado, donde, por desbidratación se transforma la glucosa en glicógeno, conforme lo 
demostro Claudio Bernard, siendo esa la forma como se acumula en ese órgano,

No es solamente en el hígado donde el glicógeno se deposita, existe también en fuerte cantidad en los músculos. Por oxidación la glucosa se cataboliza, dando como últimos términos de su combustión, anhidriđo carbónico y agua y desarrollando una energía calorígena igual a 4 calorías por gramo.

En el hígado, a medida de las necesidades de la economía, vuelve a transformarse el glicógeno en glucosa, pasando en esa forma al torrente circulatorio.

Por ese doble mecanismo de glicolisis de una parte $y$ glucogenesis de otra, es que siendo eminentemente variable la canticlad de glucosa que entra al organismo, la glicemia oscila siempre dentro de límites biev estrechos.

En la conservación del equilibrio glicémico, entran en juego muchos factores: páncreas, hígado, sistema nervioso, glándulas endócrinas, etc., cuyo conjunto forma el complejo aparato glicoregularador. Se comprende fácilmente que una afección cualquiera de los órganos que componen ese delicado mecanismo, se hará ostensible por la ruptura del equilibrio glicémico, pudiéndose presentar entonces dos contingencias: o bien, que no se pueda acumular toda la glucosa como glicógeno, o que esta sea nuy rápidamente transtormada en aquella, pasando por lo tanto el exceso directamente a la sangre para producir la hiperglicencia; o bien que, los tejidos sean incapaces de destruir la glucosa, lo que traería como consecuencia también su mayor acumulo en la sangre. Ambos puntos de vistal han sido ardorosamente defendidos pursus respectivos partidarios. Con vON NoORDEN, la mayoría de autores modernos se inclinan a creer que la hiperglicemia se produce más por sobre producción que por incapacidad de destrucción, toda vez que los tejidos son capaces de destruir cantidades verdaderamente enormes de glucosá; aún, los órganos de a nimales experimentalmente diabéticos, conforme lo ha demostrado LANDSBERG.

Admitiéndose que la hiperglicemia en la diabetes es debida a una produccion exagerada de azucar por el organismo o a una incapacidad de fijación de la glucosa, se comprende que la hiperglicemia. será tanto mayor cuanto más se aumente la cantidad de sustancias glucogeneradoras en la 
alimentación, y que disminuirá a medida que se restrinja la alimentación glucogenetica.

Conviene también decir algo sobre el metabolismo de las proteínas, toda vez que esta clase de alimentos son ab. solutamente necesarios a la conservación de la vida, porque mientras los carbohidratos y las grasas sólo sirven para producir el valor energético necesario para la actividad vital, las sustancias albuminoideas sirven para reparar las pérdidas de nuestros tejidos y en este sentido, son alimentos plásticos como los designó con mucho acierto Liebig. Hay que tener en cuenta, además, que una parte de la molécula proteica puede engendrar carbohidratos, los que van a sumarse a los que el individ to normalmente ingiere y contribuir así, al incremento de la glucosa en el organismo.

Las sustancias albuminoideas que se ingieren se diferencian enormemente de las que constituyen nuesiros propios tejidos, de modo que para poderlos reemplazar, es preciso que sufran una serie de transformaciones que les permita poder ser incorporados en el interior mismo de nuestros elementos anatómicos con una fórmula química análoga a la de ellos.

Por la acción de los jugos digestivos, las moléculas proteicas sufren una serie de simplificaciones y transtormaciones para poder ser asimiladas, desdoblándose gradualmente en los elementos más simples que las constituyen: ácidoalbúminas, albumosas, peptonas y amino-ácidos. En estas condicioues son absorbidas por el epitelio intestinal, ea donde. por combinaciones sucesivas de estas moleculas proteicas simples. reconstituyen nuevamente las sustancias albuminoideas complejas, pero de arquitectura molecular semejante a la de las que forman nuestros tejidos.

Como en la racion alimenticia habitual, las cantidades de albumina que se ingieren, son muy superiores a las necesarias para reparar los tejidos, el exceso sufre también una serie de cambios antes de ser eliminado por los emunctorios. De otro lado, las sustancias proteicas inhábiles, los productos de desecho de los tejidos destruidos o viejos, son también eliminados. El conjunto de reacciones quimicas que se operan durante la catabolisis de las proteínas, pro. porciona al organismo cierto grado de calor.

La mayor parte de las albuminas ordinarias, después de ser disgregadas y simplificadas, son eliminadas por el ri- 
ñon bajo la forma de úrea; una pequeña parte de los ácidos: animados, se eliminan en sustancia por la orina; otros, como la glicocola, se combinan en el hígado con el ácido cólico para elimivarse por la bilis como acido glicocólica.

Los glucoproteides al catabolizarse, ponen en libertad. su nucleo hidrocarbonado, que puede sufrir un metabolismo semejante al que acabo de indicar al ocuparme de los hidrocarbonados. El resto de la agrupación glucoproteica se cataboliza en la misma forma que lo hace la molécula corriente fe albumina.

El rádical nucleico de lás nucleoalbúminas, dá lugár á la formación del ácido árico y las bases xánticas. El grupo de ácido fosfórico puesto en libertad, se combina con las bases alcalinas y alcalino terrosas para eliminarse por el riñón bajo lá torma de fosfatos,

El agrupamiento sulfurado de la molécula de albámina, al cá tabolizarse dá lugà a la formación de ácido sulfárico, que inmediatamente se combina con las bases alcalinas y es elimilado como sulfato; uná pequeña parte vá a constituir los compuestos sulfoconjugados, y otrá bajo la forma de taurina y combinada al ácido cólico, es lanzada por la bilisis al intestino como ácido taurocólico.

De lo expuesto se desprende, que de la molécula proteica, se forma tamivién sustancias hidrocarbonadas capaces de hacer aumentar la hiperglicemiá en los diabéticos. Así mismo. VON NOOKDEN cree que los amino ácidos pueden en determinados casos ser fuente de produccion de cuerpos quetónicos.

Como se vé, los hidrocarbonados y las proteinas al metabolizarse van a engendrar cuerpos que en los diabéticoss harán aumentar la cifra de la glucemia. De otro lado, las proteinas pueden, en veces, engendrar compuestos cetónicos calusantes de la acidosis diabética.

Sólo me resta ocuparme del metabolismo de las grasas.

Las grasas que se toman con los alimentos van a acumularse en el organismo para constituir el tejido adiposo, principal fuente de reserva alimenticia, y el resto se, catabo. liza para suministrar a la economía la energía calorifica necesaria.

Los alimentos grasos, animales o vegetales, en las distintas fáses de la digestión son emulsionados o saponificados; en esas formas es como se realiza la absorción de ellos 
por la mucosa intestinal. Una parte va al higado para fijarse en la célula hepática; el resto penetrando por los quiheros y atravezando los ganglios mesentéricos, llega al gran conducto toráxico que acarrea las grasas al torrente eircalatorio que a su vez las lleva al pulmón, ponde, según Rogen, sufrirán un proceso de lipopexia y lipodieresis, para subvenir a las necesidades de la eeonomía, viniendo a ser el pulmón a las grasas lo que el hígado a los carbohidratos (ROGER.)

Es posible (como dice el doctor Monge) que la trecuencia de la tuberculosis pulmonar en la diabetes sea debida, al.papel-aún poco conocido-que juega el pulmón en el metabolismo de las grasas.

Una pequeña cantidad de las sustancias grasas se elimima por las secreciones sudoral y sebácea; la mayor parte es acrmulada en el tejido adiposo; y el resto, es destruido en e] organismo, dando como filtimos productos de su catabolismo agua y anhidrido carbónico; como términos intermediarios, ácidos grasos volátiles. IIna párte de estos vá a servir de núcleo a lá formación de los lipoides.

A medida de las necesidades, las grasas acumuladas en el tejido adiposo, se van quemando para proporcionar el ealor necesario a la conservación de la vida. Durante la combustión, las grasas van cada rez simplificándose más y más. Llegáda la simplificación molecular al ácido butírico, por oxidación en $B$, es éste transformado en beta-oxibutíico, el que al deshidratarse va a dar origen al ácido acetilacético que a su vez por oxidación se transformatá integramente en anhidrido carbónico y agua, como lo dije anteriormente. Esta combustión fiusl de lás grasas, es ayudada en alguna forma, sin que hasta el presente se haya podido determinar en que consiste, por la combustión simultánea de los hidratos de carbono. En circunstancias patológicas, principalmente en la diabetes, esta última faz se realiza mal; no hay una completa oxidación del ácido acetil acético, formándose entonces acetona.

Se comprende, pues, la enorme importancia que tiene, en la confección de la dieta de los diabéticos, la administración de las grasas, las que, tomadas en cantidad iumoderada, son las causantes directás de la intoxicación ácida del orgànismo.

En sintesis, en los diabéticos, el mal catabolismo de los hidrocarbonados y proteínas, conduce a la hiperglicemia; la 
incompleta combustion de las sustancias grasas, por falta de carbohidratos, y el mal metabolismo de los ácidos aminados, acarrean la acumulación y eliminación de los compuestos cetónicos, responsables de la acidosis. Son estos los dos puntos de vista principales que se deben tener siempre presentes al instituir un tratamiento antidiabético.

\section{Tratamiento}

En el tratamiento de la diabetes, dispone el terapeuta de recursos higiénicos, medicamentosos y dietéticos.

Sería extender demasiado este trabajo ocuparme detalladamente de cada uno de ellos. Solamente diré algunas palabras acerca de la higiene y de los medicamentos. En cuanto al régimen alimenticio, también podría tratar de todos los procedimientos que se han venido preconizando. pero ello seria muy largo, pues son innumerables. No se pecaria por exageración al decir que cada especialista tiene un procedimiento propio, que en veces, solo rinde éxito halagüeño en manos del propio autor, tal puede decirse de las curas de arroz de von During, las curas de patatas cle Mossi, las culas de leche de Donkin, etc., etc.

Me ocuparé con detención de las caras de aymo tan hábilmente àprovechadas por Josuin, quien ha logrado reglamentar en forma sencilla y sobre bases fisiopatológicas, Ja técnica que debe guiar al clínico en el tratamiento dietético de lá diabetes saca rina.

Higiene.-En ninguna enfermedad se debe seguir tan extrictamente los preceptos higiénicos como en la diabetes. La negligencia en el aseo personal puede originar variadas complicaciones. El prurito, síntoma bastante constante, induce a los enfermos al rascado, con lo que escorian su piel abriendo puertas de entrada a los microbios. Estas infecciones disminuirán de frecuencia si el diabético es cuidadoso de la limpieza de su piel.

Debe también el diabético evitar todo género de intoxicaciones, pues estas debilitarían mucho su resistencia orgánica. Las intoxicaciones endógenas, provocadas frecuentemente por el estreñimiento, deben ser atentamente vigiladas

Tampoco debe descuidarse la buena higiene mental; 
para ello es preciso que el enfermo evite toda clase de excesos, emociones violentas, preocupaciones, etc., que em. peorarían enormemente su estado. El pesimismo que caracteriza a los diabéticos, debe igualmente ser atendido por el médico, quien en todo caso tiene que levantar el ánimo de sus pacientes, inspirándoles confianza y arrancándoles la idea, tan extendida entre ellos, de la absoluta incurabilidad de su enfermedad. En una palabra, no debe perderse de vista los provechosos resultados de una psicoterapia bien conducida.

Los ejercicios musculares deben ser realizados cuidadosa y moderadamente, sin caer en la fatiga, con lo que se consigue un doble efecto: por un lado la disminucion de la glicosuria y aumento de la tolerancia hidrocarbonada, y por otro, recuperar la fuerza corporal y la energia espiritual, aparte de que, con los ejercicios musculares se quema cierta cantidad de glucosa. En los casos de gran desnutricion, es mas conveniente el reposo, si fuera posible en cama.

Medicamentos..-Muchas drogas han sido y son todavía empleadas en el tratamiento de la diabetes; la pluralidad de ellas dice suficientemente de su ineficacia; no quiero. afirmar con esto, que se las deba proscribir en lo absoluto, toda vez que en determinadas circunstancias pueden ser recursos fitiles. Lepine los clasifica en tres grupos:

$1^{\circ}$ Excitantes de la glucolisis, entre los que considera: los agentes oxidantes, particularmente las sales de manganeso y los álcalinos.

$2^{\circ}$ Moderadores de la glucogenia. En este grupo incluye los antipiréticos, los bromuros y el opio. Este último y sus derivados, han sido los que más han gozado del favor de los prácticos, pues posee un valor efectivo, haciendo disminuir la poliuria y bajar las cifras de la glicosuria. Puede incluirse en este grupo también, la valeriana. Y,

$3^{\circ}$ Agentes antidiabéticos de acción poco conocida. Aquí señala Leprne la piperacina, el arsénico, fósforo, hierro, cal, yoduro de potasio, sales de mercurio y multitud de otros medicamentos que han sido empleados por los médicos, y cuyos resultados, felices para unos, dudosos para otros y nulos para la mayoría, los han hecho caer poco a poco en el olvido.

En cuanto a la opoterapia pancreática que también. está considerada en este tercer grupo y de cuyos efectos se 
muestra receloso LEPINE, ha sido en los fltimos años enriquecida con un producto: la "insulina" que parece tever una acción beneficiosa incontestable. Es sensible funicamente que la vía de administración de esa droga sea la bipodérmica y que se reclamen varias inyecciones diarias.

Régimen.--En la actualidad el tratamiento de la diabetes debe ser dietético. Mientras nuestros conocimientos en lo que se refiere a la etiología y a la fisiopatologia de la diabetes, no se hayan sentado sobre bases bien solidas, que permitan oponer a cada forma clínica de la enfermedad un tratamiento que obre directamente sobre el órgano, cuyo fisiologismo perturbado, pueda ser provechosamente modificado; o, sobre el agente tóxico o infeccioso que la produce, se debe tratarde establecer en cáda diabético, su tolerancia para cada clase de alimentos, procurando que los pacientes vivan dentro de un peso normal, y administrán. doles en su dieta, el máximum de hidrocarbonados que sean capaces de metabolizar completamente, pará después ir aumentando gradualmente su tasá de tolerancia, hasta lo. grar alcanzar, si es posible, el límite normal.

Se sabe, en efecto, que un diabético que utiliza en un tiempo determinado una cantidad dada de carbohidratos, Y que sea sometido durante un tiempo mas o menos largo a un régimen alimenticio que contenga dicha cantidad de esa clase de alimentos, verá aumentar el límite de su tolerancia. Es así, como con una dieta bien calculada y rigurosamente seguida, se han realizado verdaderas curaciones de la diabetes.

La importancia de la dietética en el tratamiento de la diabetes es de antiguo conocida, y si larga es la lista de las. doctrinas patogénicas emitidas para explicar el mecanismo de la enfermedad, mucho mayor lo es todavía la de los regímenes y métodos dietético-curativos.

Solo me voy a ocupar de las curas de ayuno.

Cantani en 1880 , fué el primero en reconocer la importancia del ayuno periódico en el tratamiento de la diabetes; sin embargo, los consejos y opiniones que emitiera entonces, fueron desoídos.

Veinte años mas tarde, NAUNyN y WeInTRAod, volvieron a insistir en la utilidad de los días de hambre. "El "ayuno combinado al reposo hace disminuir las necesida- 
"des que los tejidos sienten de consumir aźcar". Tales eran los conceptos de NaUnyn y Weintra Ud, pero no dieron a su tesis la importancia que algunos años más tarde le concediera Guelpa en Francia.

En 1908 Guelpa llama la atención, por primera vez en Francia, sobre las ventajas del ayuno en el tratamiento de la diabetes. El método que exponía, consistía esencialmente en dieta hídrica, combinada con purgaciones diarias. El objeto de la dieta era colocar al organismo en la obligación de quemar sus toxinas y sus tejidos viejos; habiendo por consiguiente, una verdadera renovación de tejidos y por lo tanto, rejuvenecimiento de funciones. Administraba los purgantes, con el objeto de calmar el malestar producido por el ayuno y ayudar a la eliminación de los detritus celulares por medio de las evacuaciones intestinales frecuentes.

Con este procedimiento se veía bien pronto desaparecer las glucosurias, por abundantes o antiguas que fueran. Desgraciadamente Guelpa insistía demasiado en la importancia de los purgantes, sin tener en cuenta que era el régi. men hídrico (ayuno) el verdadero responsable de la aglucosuria de los entermos. Era tan vehemente la defensa que del valor de los purgantes hiciera Guri.pa en la Socieclad de Medicina y Terapéutica de Paris, que obligó a cleclarara Barnet en una de las sesiones que Guelpa "entonaba el himno al las purgas".

Los enfermos sometidos al tratamiento de Gurlpa, se quejaban de gran malestar y de debilidal extrema, lo que hacia que inmediatamente después de la curá, se alimenta. ran muy copiosamente, lo que traía como consecuencia el retorno rápido de la glucosuria con la misma o mayor in. tensidad que antes del tratamiento.

Lo que Guelpa conseguía con su tratamiento era sim. plemente hacer desaparecer temporalmente la glucosuria a costa de un enorme sacrificio. Fué por eso que las curas de Guecra cáyeron pronto en el descrédito.

Los alemanes, tampoco han desconocido las ventajas del ayuno en la diabetes. Von NOORDEN al intercalar en sus conocidas "curas de avena" los díls de verduras, no hace otra cosa que intercalar dias de hambre y los resultados que con ellos obtiene, son bastante demostrativos.

Ha sido en Estados Unidos de Norte America, donde mayor aceptación hán tenido las curas de ayuno. A ArLan 
corresponde la prioridad de la institución de este sistema en América. Para él, debe procurarse evitar en los diabéticos la glucosuria y la acidosis, sin preocuparse en lo absoluto de la disminución de peso de los enfermos, lo que se consigue por medio del ayuno. Conseguida la aglucosuria se debe proceder a realimentar a los enfermos, estudiando cuidadosamente la tolerancia individual para cada clase de alimentos.

Eldiox P. Josi.rn ha sido quien há trazado el plan más científico y práctico para llevar a cabo las curas de hambre. Siguiendo sus indicaciones es que he tratado los enfermos cuyas historias acompaño para ilustración de este trabajo.

El método de Josuin para el tratamiento de la diabetes ha dado los resultados más halagadores en el Hospital General de Massachusets, pues mientras la mortalidad por esa enfermedad en los 90 años que precedieron a 1914 fué de $28 \%$, desde entonces, que se viene aplicanclo el método, há bajado a $7 \%$.

Para llevarlo a la práctica, es menester que el médico y el paciente marchen enteramente de acuerdo. Es necesario que aquel instruya a éste sobre su enfermedild, para que de ese modo tuo y otro contribuyan al mejor éxito de la cura.

Llevando al convencimiento de los enfermos la utilidad de la dieta que se les instituye, se alejan las probabilidades de los fraudes y excesosque con tanta frecuencia cometen los diábéticos.

Si el enfermo es persona instruída e inteligente, es conve. niente enseñarle a investigar y dosar la glucosa y el ácido acetilacético para que pueda él mismo controlar el estado de su orina, sobre todo después de habérsele dado de altú en el tratamiento. En el momento que el paciente nota la reducción del licor de FeHLing, comprende la agravación de su enfermedad y acude nuevamente donde el médico a consultarse de su estado. De otro lado, puede él mismo apreciar las variaciones diarias en la eliminación de la glucosa, y las rentajas de una dieta bien llevada.

El plan curativo de Joscin, comprende:

I).-Preparación para el aruno.-El enfermo es lleva. do progresivamente al ayuno, para lo cual los dos primeros dias de tratamiento, se suprimen por completo las grasas de la alimentación, sin cambiar en nada el resto del régimen ordinario; los dos días subsiguientes, se suprimen además, los albuminoideos; después se reducen paulatinamente los carbo- 
hidratos hasta que sólo se consuman 10 gramos de ellos. En seguida ayuno. En otros casos puede llevarse el ayuno al cuarto o quinto día.

El objeto de esta fáse preparatoria, es la previsión de la acidosis. La intoxicación ácida del organismo es debida a la combusti6n imperfecta de las grasas por falta de carbohidratos. La ingestión de hidratos de carbono en los primeros dias facilita grandemente la combustión de las grasas que pudieran existir en exceso y que, incompletamente metabolizadas, darian lugar a la formación de los compuestos quetónicos.

Después de la omision de las grasas en la dieta, se excluyen las proteínas. El objeto de esto es alejar más aún la posibilidad de la acidosis y aproximar el ayuno.

II).-Fase de ayuno.-Cuatro dias de ayuno absoluto, a menos que la ausencia de la glucosuria nos permita disminuir el numero de días de hambre.

El objeto del ayuno es conseguir la aglucosuria. Por regla general, salvo casos muy antiguos o de grandes glucosu. rias con fuertes hiperglicemias, al segundo o tercer día desaparece el aźcar de la orina.

Durante el ayuno los enfermos sienten ungran hienestar, pues, a la vez que disminuyen la poliuria y la polidipsia, mejora grandemente el estado general. En este período puede permitírseles a los enfermos la ingestión de té, café, caldos ralos y agua a voluntad.

En los enfermos que be trátado, el ayuno lo he llevado a cabo en una forma no muy rigurosa. Al caso $\mathrm{N}^{\circ} \&$ que fue el que se presentó más rebelde, le permitía tomar, durante el periodo de ayuno, una taza de caldo completamente desprovisto de grasa, cada 3 horas; a ese caldo le añadía pequeñas cantidades de vegetales al $5 \%$ que habian sufrido 3 cocciones sucesivas, con el objeto de liberarlos absolutamente de hidratos de carbono.

El caldo cuyo valor nutritivo es nulo, en lo que se refiere a carbohidratos, proteínas y grasas, pues solo contiene sales minerales y vitaminas, goza entre los profanos del pres. tigio de tener gran valor nutritivo, lo que puede utilizarse para mantener durante cierto tiempo el ayuno, sin que los enfermos sientan temor a la desnutricion. Cuando los pacientes se muestran muy debilitados, puede también permitirseles cierta cantidad de alcohol durante este período de la cura. 
Mientras están en ayuno, Josuin permite que sus enfermos se levanten y ejecuten marchas moderadas, recomendándoles muy especialmente el reposo mental. Me parece más conveniente que los pacientes guarden cama el mayor tiempo posible durante este período, toda vez que cualquier movimiento representa un desgaste de energía que no se re. pone. He recomendado, pues, a los enfermos durante el ayuno, la permanencia en el lecho, evitándoles también toda clase de trabajo in telectual.

III).-Ayuno intermitente. $-\mathrm{Si}$ al fin de los cuatro días de hambre, la glucosuria persiste, se les dará durante dos días uns alimentación reducida, consistente en un gramo de proteínas o medio gramo de carbohidratos por kilo de peso. Después de esto, 3 días nuevamente de ay uno. Si persiste la glucosuria, se hará nuevamente una comida análoga a la expresada anteriormente, que se debera tomar por espacio de dos días y uno o dos días de ayuno, si fuera necesario. Por último, si la glucosuria persistiera aún, se dará cuatro -días de régimen exilusivo de proteínas y un día de ayuno. En cuanto se obtenga la aglucosuria, se irán aproximando los días de alimentación y alejando los de ayuno, hasta que éstos solo se observen una vez por semana.

Este procedimiento debe de reservarse a los casos graves, en los que, los diabéticos muy avanzados continuán formando azficar a expensas de sus propios tejidos. No he tenido ocasión de observar ningún caso de estos. Todos los que he podido seguir, han cedido a los primeros días de ayuno. En algunos, ha sido suficiente con bajar gradualmente las cantidades de alimentos, para dar cuenta de la glucosuria.

IV).--Realimentacion.-Obtenida la aglucosuria, se debe de proceder a alimentar progresivamente a los enfermos, teniendo cuidado de estudiar, concienzudamente, la tolerancia de cada uno de ellos para los carbohidratos, proteínas y grasas.

a) Tolerancia por los carbohidratos.-Lu primero que se debe de establecer es la tolerancia para los hidratos de carbono.

Obtenida durante 24 horas la ausencia de glucosa en la orina, se permitirá al enfermo una pequeña cantidad de hidrocarbonados, aproximadamente de 5 a 10 gramos. La forma mas conveniente de administrarlos es como vegetales pobres ( 5 a $10 \%$ ). Se contináa después aumentando diariaim ente los carbohidratos de 10 en 10 gramos o menos, hasta 
la reaparición de la glucosuria, lo que marcará precisamente el límite de tolerancia para esa clase de alimentos.

Para conocer la riqueza en carbohidratos de los distintos alimentos, se cuenta con tablas especiales. He hecho usode las proporcionadas por JosLin, en las que, están clasificados los alimentos en cuatro grupos segun su valor en hidratos de carbono, como puede verse en la tabla $\mathrm{N}^{\circ} 1$.

Debe de tenerse en cuenta que con la ebullición, los vegetales pierden el $2 \%$ de su ricueza en hidrocarbonados. I'rácticamente, los vegetales al $5 \%$, después de 3 ebulliciones, están exceutos por completo de carbohidratos, conteniendoúnicamcnte celulosa, circunstancia que como ya lo he dichor he aprovechado para poder tar a los enfermos durante los días de ayuno cierta cantidad de alimentos, que haciendo volumen pueden disimular el hambre, sin proporcionar al. organismo ningan valor glucogenético.

Gradualmente se va permitiendo vegetales cada rez más. ricos $(15$ y $20 \%)$ y si los enfermos presentan buena tolerancia, se les puede administrar, en último término, pan que contiene 18 gramos por onza.

Puede también administrárseles fruta. En la tabla $N^{\circ} 2^{\circ}$ y que tambien he sacado de Josirn está expresada la rique-za en carbohidratos de las frutas más corrientes.

b) Tolerancia por las proteínas.--Conseguida la aglucosuria durante 2 o 3 días, se comienza a administrar proteinas. Se dan 20 gramos de albumina la primera vez y después se adicionan de 15 en 15 gramos las proteínas, diariamente hástá que el enfermo ingiera 1 gramo de albuminoideos por kilo de peso. En caso de que la tolerancia por los. hidrocarbonados sea muy pequeña, debe aumentarse proporcionalmente la cantidad de proteínas.

La forma más conveniente para administrar la albúmina, es el pescado que contiene 6 gramos de albumina pura por onzá, y cási no contiene grasa. Puede también, en lugar de pescado, darse claras de huevo, cuya riqueza en proteínas es a proximadamente de 6 gramos cada una.

En la tabla $N^{\circ} 3$, se encuentra expresada la riqueza en. carbohidratos, proteinas y grasas de los principales alimentos, y es la que me ha servido de norma para el cálculo de las raciones alimenticias.

A los niños se les debe dar mucho mayor cantidad de sustancias proteicas: 2 a 3 gramos por kilo de peso, segun 
la edad, Cuanto más joven es el indivíduo, tanta mayor cantidad de sustancias albuminoideas debe dársele en sus alimentos.

La administración simultánea de proteínas y carbohidratos, tiene la ventaja de aproximar más el régimen del enfermo, a las condiciones normales de alimentación, pudiéndose así mismo, hacer más variada la dieta y por consecuencia mucho mejor tolerada.

En los entermos que he tratado, en cuya mayoria no se han presentado grandes dificultades para la produc ción de la aglucosuria, no he esperado 72 horas de ausencia de aźcar en la orina, para comenzar a administrar las proteinas. En los casos en los que el ayuno ha sido innecesario, be tratado de da lo más rápidamente posible la cantidad correspondiente de proteínas, con el objeto de esta* blecer, a la brevedad posible, el balance de sus alimentos, evitando así, hospitalizaciones demasiado prolongadas.

c) Tolerancia por las grasas.-No se debe permitir la ingestión de grasa a los enfermos, mientras existan signos de acidosis o glucosuria. Son dos las razones que deben de pesar en el ánimo de los médicos, para evitar la administración de la grasa a los diabéticos, mientras estén glucosuricos. Ellas son: $1^{0}$ la obtención de un aumento de la toleranciá hidrocarbonada, y $2^{\circ}$ la desaparición de las sustancias quetónicas, responsables de la acidosis.

Tan luego como el enfermo ha llegado a tomar un gra. mo de proteínas por kilo de peso, se debe proceder a agregar las grasas en la ración alimenticia.

Establecida en el enfermo, la tolerancia por los carbohidratos y las proteínas, conforme he indicado, se debe completar el valor calórico necesario con grasa, en forma tal que el indivíduo tome en sus alimentos 30 calorías por kilo de peso.

Los cálculos calóricos, son sencillos, conociendo que:

1 gramo de carbohidratos produce en 24 boras 4 calorías

1 " de proteínas

y 1 ", de grasas

$\begin{array}{lllll}" & 24 & , & 4 & , \\ , & 24 & , & 9 & ,\end{array}$

V).-Reaparición de la glucosuria.-El retorno del azG. car en los diabéticos que han permanecido durante largo tiempo aglucośricos, demanda un día de ayuno absoluto, $\mathrm{y}$ análisis de orina a las 24 horas que siguen al ayuno, no 
debiendo realimentarse al enfermo mientas permanezca glucosúrico, sino en armonía con el balance establecido antes del retorno de la glucosa.

VI).-Ayuno semanal--En los enfermos cuya tolerancia por los carbohidratos es muy débil, conviene instituirse. manalmente un día de ayuno, que sirve para que el orgamismo transforme o asimile el exceso de glucosa que pudiera tener.

Tal es, sintéticamente expuesto, el plan curativo de Joslin, que he puesto en práctica en los enfermos que he tratado en el Hospital de Santa Ana.

Como lo hace notar el propio autor del método, con su procedimiento se obtienen cuatro ventajas utilisimas, que basta con enumerarlas para que sirvan de recomendación al tratamiento, y son:

$1^{\circ}$ Prevención de la acidosis.

$2^{\circ}$ Determinación de la tolerancia individual para los carbohidratos.

$3^{\circ}$ Educación del paciente y su colaboración con el médico; y

$4^{\circ}$ Sustracción del enfermo a lá desnutrición por e empleo discreto del ayuno.

No podría concluír este trabajo, sin hacer alusión a las comunicaciones que desde el año 1920, vienen haciendo Newburgh, Marsh y otros, sobre las ventajas de la dieta altamente grasosa en el tratamiento de la diabetes sacarina; sistema que hace muchos años pas 6 a la Historia, y que es precisamente antagónico del que es motivo de esta tesis.

La fnica enferma balanceada por el procedimiento de STRouse, panegirista del sistema fuertemente grasoso, me dió los más desastrosos resultados, poniendo seriamente en pligro la vida de la paciente como puede verse en el caso Ne 3.

Ultimamente NewBorgh mismo, enmienda rumbos al decir que "el uso de tal dieta grasosa, puede ser justificado "unicamente, cuando la grasa adicional no aumenta la " propension del enfermo a la acidosis". 
TABLA Nי 1

VALOR DE LOS VEGETALES EN CARBOHIDRATOS

\begin{tabular}{|c|c|c|c|}
\hline $5 \%$ & $10 \%$ & $15 \%$ & $20 \%$ \\
\hline echuga & Calabaza......... & Arvejas.. & rapas. \\
\hline Pepino.......... & Nabo ................. & Frijoles verdes. & Canıotes \\
\hline ispinac a...... & Zanahoria....... & Alcachofa ........ & Yuca....... \\
\hline Espárrago... & Zapallo.... & ... & Arroz.... \\
\hline Escarola....... & Hongos.... & & Choclo..... \\
\hline ........... & Caiguas .......... & $\ldots .$. & Menestras \\
\hline Coliflor.......... & 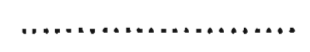 & ......... & \\
\hline Vainitas....... & ........... & ........... & \\
\hline Rábano........ & …............ & .... & \\
\hline Cebollas....... & n............. & & \\
\hline Apio & .... & & \\
\hline Tomate & ...... & .... & \\
\hline e ......... & $\ldots \ldots \ldots \ldots \ldots$ & ........ & \\
\hline$\ldots \ldots \ldots$ & ............... & $\ldots \ldots \ldots$ & $\cdots$ \\
\hline S. & ....... & ..... & \\
\hline
\end{tabular}

TABLA $\mathrm{N}^{\circ} 2$

VALOR DE LAS FROTAS EN CARBOHIDRATOS

\begin{tabular}{|c|c|c|c|}
\hline $5 \%$ & $10 \%$ & $15 \%$ & $20 \%$ \\
\hline - & - & - & - \\
\hline Fresas. & Naranjas ................. & Manzanas....... & las \\
\hline Limón ........ & Sandia. & Peras............... & Plátanos \\
\hline Mora......... & Granadilla.............. & Peros ............. & $\cdots$ \\
\hline (n)................. & Tunas................. & Cerezas ........... & ….... \\
\hline .... & Melocotones........... & Uvas ............... & ...... \\
\hline ... & Piña.. & Chirimoya..... & \\
\hline
\end{tabular}


TABLA $\mathrm{N}^{9} 3$

COMPOSICIÓN RELATIVA DE LOS ALIMENTOS (POR ONZA)

30 gramos de:

Avena

Leche

Carne

Un huevo

Vegetales al $5 \%$

,

,

,

Pan

Pescado.

, 10 ,

, 15 ,

, 20

,

Mantequilla

Aceite

Conchas y mariscos
Carbohidratos

20.

1,5 .

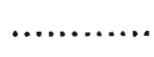

1.

2,5 .

4.

6.

18.

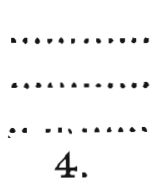

Proteinas

5.

1.

8.

6.

0,5

0,5

0,7

1.

3 ,

6.

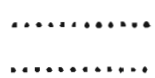

6.

\section{Grasas}

2.

1.

3.

6.
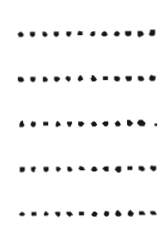

25.

30.

1. 


\section{CASUISTICA}

Hospital de "Santa Ana" Servicio médico del Dr. Monge

\section{Historia Clinica $N^{9} 58$}

Sala de "San Miguel" Cama $N^{\circ} 14$

C. $P$, de 58 años, negra, peruana, domiciliada en Barranco y de oficio cocinera, ingresó al servicio el 15 de diciembre de 1922.

Antecedentes hereditarios.--Padres muertos, ignora de qué; cuatro hermanos vivos. sanos; ocho hermanos muertos en distintas edades y de diferentes entermedades.

Antecedentes personales:

Fisiológicos.-Primera dentición y marcha normales; segunda dentición algo retardada. No ha hecho vida escolar; tampoco há tenido vida sexual. Primeras reglas a los 11 años, de 2 días de duración; no ha tenido desarreglos. Menopausia desde los 50 años.

Patologicos.--Sarampión, viruela y angina en su irfancia. A los 46 años fué operada de várices de la pierna derecha. Desarreglos gastrointestinales y catarros nasales y bronquiales con relativa frecuencia. Fuerte infeccion dentaria; a los 20 años había perdido los incisivos interiores. Hace 2 años, paludismo. de 6 meses de duracion. Constipación crónica. No ticne hábitos alcohólicos, ni ha hecho uso de ningún tóxico. Ulcera del pié derecho á nivel de la cabeza del primer metatarsiano desde el mes de setiembre.

Eafermedad actual.-No recuerda precisamente el principio de su enfermedad. Aproximadamente desde bace 8 años, se inició su enfermedad con prurito intensísimo que no le permitía dormir; poco tiempo después notó que se adelgazaba y era presa de una gran laxitud; al propio tiempo tenía sed ardiente, el a petito era exagerado y presentaba abundante poliuria, sobre todo nocturna. El año 1919, le hicieron por primera vez análisis de orina, comprobándose 
la presencia de glucosa. Un año más tarde se estuvo atendiendo en la sala de "La Virgen" de este mismo hospital, de una lesión supurativa del pié derecho; antes de ser operada, refiere la enferma que "estuvo a la muerte"; pasado ese estado de gravedad permaneció 8 días en cama con una hemiplegia derecha; el análisis de orina practicado entonces, revelo también la existencia de glucosa. Fué sometida a un régimen apropiado y después operada. Meses más tarde tue dada de alta en perfecto estado de salud; la glucosuria habia desaparecido y la enferma había ganado en peso. En su casa la enferma descuidó por completo su alimentación, volviendo a adelgazarse. En el mes de setiembre, presentó intensos dolores en la planta del pié derecho, a los pocos días le a pareció a ese nivel una excoriación que fué ganando en dimensiones y profundidad, al punto de dificultarle grandemente la deambulación. En esas condiciones solicitó ser hospitalizada.

EXAMEN CLÍNICO-16 DE DICIENBRE DE 1922

Desarrollo, regular. Actitud tranquila. Emaciación marcada. Cicatriz operatoria en la pierna derechá. Peso 113 libras.

Cabeza. Craneo dolicocéfalo. Cuero cabelludo con pequeñas zonas de alopecía. Conjuntivas subictéricas. Pupilas iguales, reaccionan bien a la luz y a la acomodación. Visión disminuída.

Mucosa bucal normal. Lengua humeda y limpia, tuerte olor acetónico del aliento. Ausencia completa de todas las piezas dentarias.

Cuello cilind rico, no hay estruma palpable.

Torax ligeramente aplanado en sentido antero-posterior.

Pulmones sin particularidades. Respiración de tipo costo-abdominal. 19 respiraciones al minuto. No bay tos ni espectoración.

Pulso duro. de ritmo regular, late 90 veces al minuto. Tensión arterial Mx: 17,5; Mn: 10; Dif: 7,5 al Tycos. Reforzamiento del segundo tono aórtico. Arterias duras, ruedan bajo el dcdo. Venas algo varicosas.

Infarto de los ganglios inguino-crurales derechos. 
Vientre excavado, depresible e indoloro, de timpanismo normal. Se palpa cuerda cólica. Higado normal, no se palpa vesícula biliar.

Espacio de Traube libre. No se palpa bazo.

Funcion digestiva: polifagia; digestiones normales; constipación.

Nada de particular al exámen del aparato genital. Poliuria y nicturia. Extremidades superiores, normales.

La piel del pié derecho presenta un aspecto apergaminado y negruzco; mal perforante plantar al mismo lado; ulceración en el pulpejo del dedo gordo.

Sensibilidad, motilidad y reflejos, normales.

Inteligencia, buena. Na rcolepsia.

Reacción de WassermanN, negativa.

Análisis de orina: 7,5\% de glucosa; trazas de albumina y fuerte cantidad de acetoná. Los demás elementos de la orina, no ofiecen particularidades.

Diagnóstico: Diabetes Sacarina. Mál perforante plantar.

Al cuarto día de ay tuno (23 de diciembre) desaparece la: glucosuria; la ulceración de la planta del pié, mejora día a día, la pequeña pérdida de sustancia del pulpejo del dedo. gordo, cicatriza rápidamente y desaparece completamente el olor acetónico del aliento.

Se comienza a realimentar a la enferma, a pareciendo una ligera glucosuria el 29 de diciembre, que persiste hasta el 12 de enero de 1923. El mal perforante plantar, cicatriza completamente en los primeros dias de enero.

Se establece el balance alimenticio de la enferma, en la siguiente forma: Carbohidratos: 110 gramos. Proteínas: 68 gramos. Grasas: 110 gramos. Lo que rinde aproximadamente 1700 calorías.

Fué dada de alta el 5 de febrero de 1923 , en muy buenas. condiciones, habiendo aumentado 2 libras de peso. 


\section{CASO $\mathbf{N}^{\circ} 2$.}

Hospital de "Santa Ana" Servicio médico del Dr. Monge.

Historia clínica $N^{\circ} 107$.

Sala de "San Miguel". Cama $N^{\circ} \mathrm{XO}$.

R. Ch. de A., negra, casada, peruana, vecina de Pisco y de oficio lavandera, ingresó al servicio el 3 de febrero de 1923.

Antecclentes personales:

Fisiológicos:-Primera y segunda dentición, normales, precocidad en la marcha y la palabra. Primeras reglas a los 13 años, sin desarreglos. 3 partos de término. Hábitos al. cohólicos moderados. Abusos en la alimentación, particularmente farináceos y azúcares.

Patológicos:-Ha sido muy sana en su infancia. Congestión pulmonar a los 18 años. El año 1914, vino por primera vez de Pisco, para atenderse de unas metrorragias; el médico que la trataba le manifestó que en su orina existía albúmina y glucosa y la sometió a un régimen alimenticio, con el que mejoró considerablemente. Grippe el año 1918. Leucorrea y metrorragias abundantes desde el mes de diciembre del año 1922. Desde esa época, adelgazamiento; pues dice háber sido excesivamente gordá.

Enfermedad actual:-Desde los primeros meses del áno 1919, se inició su enfermedad, con malestar general, dolores lumbares, narcolepsia, polidipsia, polifagia y poliuria; poco tiempo después le ápareció prurito vulvar, tan intenso, que la obligaba a hacerse aplicáciones de ungüentos calmantes. Refiere la enferma, que no obstante alimentarse abundantemente, se adelgazaba en forma alarmante. Se consultó entonces con un médico. quien le hizo un análisis de orina que puso de relieve la existencia de azúcar. A partir de aquella fecha, comeuzó a sentir cefaleas pertinaces y sus reglas catameniales, se hicieron irregulares. En el mes de junio de 1922, notó la aparición de dísnea de esfuerzo y palpitaciones. En los primeros días de diciembre, fué sorprendida por una 
abundante metrorragia, la que se repiti6, con los mismos caracteres alarmantes, 15 días mas tarde. Desde entonces, las hemorragias se suceden constantemente, acompañadas de fuertes dolores hipogástricos. A fines de enero del año en curso, pudo apreciar la enferma, la presencia en su vientre, de una tumoracion redondeada, del tamaño de un huevo de gallina. Alarmada por la presencia de ese tumor, vino a la capital, habiéndosele diagnosticado, fibroma uterino, recomendándosele, se hospitalizara para operarse. Entró al servicio.de Ginecología del Dr. B E L L o, de este mismo hospital, de donde la pasaron a nuestra sala, por glucosuria.

\section{EXAMEN CLINICO 4 DE FEBRERO DE 1923.}

Desarrollo bueno. Actitud tranquila. Grueso panículo adiposo. Peso 156 libras.

Cráneo subdolicocéfalo. Cuero cabelludo normal; abundante cabello, bien implantado. Conjuntivas pálidas, pupilas isocóricas, reaccionan bien. Visión disminuida. Lengua hameda y limpia, mucosa bucal, normal. Faltan 4 piezas dentarias. El resto en buen estado de conservación.

Cuello cilindrico. No se palpa la tiroides.

Torax, bien conformado. Pulmones, sin particularidades. Tipo respiratorio costo-abdominal. 20 respiraciones al minuto. No hay tos ni expectoración.

Pulso duro y rebotante, de ritmo irregular, pues se nota una que otra falla, late 88 veces al minuto. Tensión arterial: Mx. 200; Mn. 100; Dif. 100. Soplo sistólico suave en .el foco aórtico. Arterias esclerosadas; venás normales. Adenopatía inguino-crural izquierda.

Vientre abovedado; grueso panículo adiposo. Tumoración redondeada a 2 traveces de dedo por encima de la sínfisis del pubis. Ligera pastosidad en los dos cuadrantes inferiores del abdomen. Punto doloroso ovárico izquierdo. Sonoridad normal. Gorgoreo en la fosa iliaca derecha.

Higado normal e indoloro. No hay dolorabilidad en el punto cístico.

Espacio de Traube, libre. No se palpa el bazo.

Función digestiva: Polifagia; digestiones lentas, constipación.

Apara to genitourinario: Utéro en anteflexion, de superficie irregular, aumentado de volumen y movible, fondos de saco libres. Dolorabilidad en el anexo izquierdo. 
Extremidades, sin ninguna particularidad.

Sensibilidad y motilidad, normales.

Abolición del reflejo rotuliano. No hay BabINski.

Inteligencia, buena. Sueño tranquilo.

Reacción de WasSERMAN negativa.

Trazas de albúmina, $10 \%$ de azúcar y regular cantidad: de acetona, son los elementos que llaman la atención en la. orina.

Diagnóstico: Diabetes sacarina. Fibroma uterino. Insuficiencia aórtica?

Al quinto día de régimen, desapareció la glucosuria, para reaparecer 4 días más tarde, cuando la enferma tomaba. 112 gramos de carbohidratos. No obstante la disminución progresiva de la cantidad de hidrocarbonados, la glucosuria persistió, reclamando dos días de ayuno, cou lo que se obtuvo definitivamente la ausencia de azGcar.

El día 25 de febrero, a parecen nuevamente trazas de glucosa, lo que coincide con la presencia del flujo merstrual, y que me parece, se debió al hipertiroidismo que ese acto provoca, la glucosuria desápareció a lás 24 horas, a pesar de mantenerse fija la cantidad de carbohidratos en la dieta.

Permaneció aglucosúrica, la enferma, hasta el 3 de mar$z o$, en que se le administran 102 gramos de carbohidratos, que provocan la excreción de trazas de glucosa, las que desaparecen en cuanto se baja la cantidad de hidratos de carbono.

Se establece, como tolerancia máxina 90 gramos de carbohidrátos.

Desde el 8 de marzo, se confeccionan dietas que contienen:

85 gramos de carbohidratos; 65 de proteínas y 147 de grasas, que producen un valor calórico igual a 1900 calorías, mas o menos.

La enferma, bastante aliviada, y no encontrándose en: ánimo de ser operada de su fibroma uterino, solicitó su alta. el 15 de marzo.

A su salida, le entregué un apunte, en el cual le indicaba, precisamente, las cantidades y clases de alimentos que debía tomar diariamente. Una semana más tarde, regresó de visita al Hospital, y en el examen de orina que se hizo no seencontró ninguna clase de elementos anormales. 


\section{CASO $\mathbf{N}^{\circ} 3$.}

Hospital de "Santa Ana". Servicio médico del Dr. Monge Historia Clinica $N^{\circ} 88$.

Sala de "San Miguel" Cama $N^{\circ} 9$.

T. G., de 52 años, mestiza, viuda, peruana, domiciliada en la calle de "5 esquinas" y de ocupación cocinera, ingresó al servicio el 16 de enero de 1923.

Antecedentes hereditarios.-Padre muerto de accidente del trabajo; la madre de difteria; dos hermanos muertos, uno de ellos padeció en vida de ataques epilépticos. 6 hijos, 2 muertos de neumonia, 4 vivos, sanos. Un aborto.

Antecedentes personales:

Fisiologicos.-Primera y segunda dentición normales; reglas ca tameniales desde los 15 años, de 4 días de duración, no ha tenido desarreglos. 6 partos de término, en uno de ellos tuvo infección puerperal; un aborto. Menopausia hace 6 años. Buenos hábitos higiénicos.

Patologicos.-En su primera infancia solo padeci6 de sarampión y viruela. A los 23 años fué operada de osteomiel:tis del humero derecho. A los 36 años blenorragia complicada de artritis del codo derecho, habiéndose anquilosado desde entonces la articulación húmero antebraquial correspondiente. Catarros bronquiales con relativa frecuencia. Forunculosis el año 1921. Paludismo de corta duración el año próximo pasado.

Enfermedad actual.-Refiere la enterma que las primeras manifestaciones de su enfermedad, se remontan al año 1920 , en que presentó poliuria nocturna, polidipsia y polifagia. Desde entonces, a pesar de comer abundantemente, sentía profunda astenia y se adelgazaba en forma alarmante. Continuó en ese estado hasta el mes de agosto de 1921, en que, un análisis de orina, puso en evidencia la existencia de azGcar en fuerte cantiład. A indicación de su médico, se some- 
tió a un régimen apropiado, con lo que mejoró ligeramente. Algunos meses más tarde fué a tacada de paludismo, lo que agravó su glucosuria; se hospitalizó en este servicio, donde permanecio 16 días, al cabo de los cuales había curado su paludismo y mejorado su glucosuria. Permaneció en su domicilio hasta su reingreso al hospital, descuidando por com. pleto el régimen que se le instituyó. A su vuelta al Hospital, se queja de dolores al cuerpo, somnolencia exagerada, laxitud general, polidipsia y trastornos oculares (pérdida de la agudeza visual).

\section{EXAMEN CLÝNICO. 16 DE ENERO DE 1923.}

Desatrollo proporcionado. Actitud indiferente. Ligera demacración. Piel seca, pústulas de ectima en las piernas, cicatriz operatoria en el brazo derecho, anquílosis del codo del mismo lado. Peso 135 libras.

Cráneo braquicéfalo. Cuero cabelludo normal, abundante cabello entrecano, bien implantado. Conjuntivas subictéricas. Pupilas isocóricas, reaccionán bien a la luz y a la acomodación. Visión disminuida. Mucosa bucal sin ninguna particularidad, lengua húmeda y limpia. Dientes incompletos; algunas piezas cariadas. Ligerá desviación del tabique nasal al lado derecho. Olfación buena, audición normal.

Cuello cilindrico. No se percibe la tiroides a la maniobra de Marañón.

Torax bien conformado. No hay particularidades en el aparato respiratorio.

Pulso blando y depresible, de ritmo regular, late 68 ve. ces al minuto. Tensión arterial: $\mathrm{Mx}:$ 130. Mn: 70. Dif: 60 . Nada de particular en los ruidos del corazón. Arterias elásticas. Venas normales.

No hay infartos ganglionares.

Vientre escavado, depresible e indoloro. Cólon descen. dente ocupado.

Higado basculado. No se palpa la vesícula biliar.

Espacio de Traube, libre. Bazo de dimensiones normales.

Función digestiva: Hiperorexia; digestiones buenas; constipación.

A parato genital sin particularidades. Nicturia.

Extremidades superiores. Anquilosis del codo derecho; cicatriz operatoria en el brazo.

Extremidades inferiores normales. 
Sensibilidad, motilidad y reflejos, normales.

Inteligencia, buena. Narcolepsia.

Reaccion de WassermanN, negativa.

En el análisis de orina, se comprobó fuerte cantidad de acetona; 0,60 grms. de albumina y $3,1 \%$ de glucosa. Los demás elementos, no ofrecen in terés especial.

Diagnóstico: Diábetes sacarina.

En los primeros días de su estadía en el Hospital, se somete a la enterma, a fuertes cantidades de carbohidratos, para evitar la formación de cuerpos quetónicos.

El día 20 de enero, se aplica la fórmula de STRouse para bacer el balance rápido de la enferma, prescribiéndose, por consecuencia, una dieta altamente grasosá. Al siguiente día la enferma presentó signos gravísimos de acidosis e inminencia de coma. La glucosuria bajó notablemente, pero aparecieron fuertes cantidades de ácido acetilacético y de acetona. La acidosis medida según el procedimiento de VAN SLXKE arrojó la cifra aterradora de 23,41 . La enfermá se quejaba de opresión al pecho, dísnea y tenía un marcado olor acetónico en el aliento. En estas condiciones, suprimimos las grasas de la alimentación, se bajó la cantidad de proteínas y se incrementaron los carbohidratos. Su estádo mejoró. Cuarentaiocho horas más tá rde, la parte dramática del cua. dro, habia pasado, y la enferma entraba en un período de franca mejoría.

Desde los primeros días de febrero, se procede a realimentarla, ciñéndome extrictamente a las indicaciones de Joslin. Reapareció la glucosuria, cuando la enferma tomó 187 gramos de hidrocarbonados.

El balance se estableció con: $187 \mathrm{grms}$. de carbohidratos 70 de proteinas y 110 de grasas con un valor de 2,000 calo. rías aproximadamente.

Fué dada de alta en inmejorables condiciones el 28 de febrero, recomendándosele, siguiera extrictamente la dieta que por escrito se le entregó.

Por espacio de dos meses continúo consultándose en el servicio, cada semana; en ninguno de los análisis que se hizo se encontro elementos anormales en la orina. 


\section{CASO No 4}

Hospital de "Santa Ana" Servicio médico del Dr. Monge Historia clinica $N^{\circ} 118$.

Sala de "San Migüel". Cama $N^{\circ} 22$

I. A. de L., de 29 años, india, casada, peruana, vecina de Cerro Azul, ingresó al servicio el 16 de febrero del año en curso.

Antecedentes hereditarios.-Padre muerto de extrangu. lación herniaria; madre viva, sana; 12 hermanos de los cua. les solo viven 5 ; los demás murieron en su primera infancia; 5 hijos: 2 viven, 3 murieron a los pocos dias de nacidos.

Antecedentes personales:

Fisiologicos.-Dentición y marcha, normales. Reglas ca. tameniales a los 14 años, de 5 dias de duracion; no ha padecido de desarreglos. Cinco partos de término y dos abortos.

Patologicos.-Sarampión, parotiditis y catarros bron. quiales en su primera infancia. La enferma hace gala de haber sido muy sana y solo haber guardado cama por sus partos. Quemaduras extensas en la rodilla izquierda a la edad de 15 años. Forunculosis el año 1919. No hay hábitos alcobólicos.

Enfermedad actual.--Desde el mes de noviembre del año pasado, la enferma presentaba, sed intensa, polifagia y poliuria nocturna; algunas semanas más tarde tuvo "descomposición del cuerpo" y sudores profusos. En ese estado vino a Lima a consultarse con un médico, quien ordenó se le hiciera un análisis de orina, en el que se comprobó la existencia de 166 gramos de glucosa por litro. Fué sometida a un régimen alimenticio pobre en hidrocarbonados. Un mes más tarde, se le practicó ur nuevo análisis de orina, constatándose la glucosuria en fantidad casi igual a la primera vez, al mismo tiempo que una fuerte cantidad de acetona. El médi. co tratante, le recomend6 que se hospitalizara, lo que hizo pocos días después. 
EXAMEN CLINICO 16 DE FEBRERO DE 1923

Desarrollo proporcionado. Actitud indiferente. Emaciacibn pronunciada. Piel sudorosa, numerosas vergeturas en el abd6men, cicatriz en la rodilla. Peso 68 libras.

Craneo subdolicocéfalo. Cuero cabelludo normal. Conjuntivas pálidas. Pupilas isocóricas, reaccionan pesadamente. Leucoplasia bucal. Paraqueratosis lingual. Olor acetónico del aliento. Dientes incompletos, en pésimo estado de conservación; todas las piezas cáriadas. Encías con fuliginosidades negruzcas: Lijera hipertrofia de la amigdala derecha. Olfación y audición normales.

Cuello cilindricn. No se palpa la tiroides.

Torax a planado en sentido ántero-posterior, retracción de los espacios intercostales y de las fosas supra e intraespinosas. Red renosa subcutánea en el hemitórax derecho. Signos de condensación, poco manifiestos en el vértice derecho. Tipo respiratorio, costal inferior. 18 respiraciones al minuto. No existe tos ni expectoración.

Pulso blando y depresible, de ritmo regular, frecuencia, 68 al minuto.

Tension arterial: $\mathrm{Mx}$ 110; Mn: 70; Dit: 40 al Tycos. Desdoblamiento del $2^{\circ}$ tono pulmonar. Arterias elásticas; venas normales.

Poliadenia generalizada.

Abdomen excavado, depresible e indoloro. Ligera hipertrofia del hígado. No hay dolorabilidad en el punto cistico.

Espacio de Traube libre. No se palpa bazo.

Función digestiva: Hiperorexia; digestiones regulares defecación normal. ria.

Nada de particular en el aparato genitourinario. Poliu-

Sensibilidad y motilidad, normales. Ausencia del reflejo rotuliano; los otros reflejos, responden pesadamente.

Inteligencia mediocre. Narcolepsia.

Reacción de WASSERMANN negativa.

Cutireacción de von PIRquet negativa.

Al examen de la orina, se encuentra $9 \%$ de glucosa, fuerite car idad de acetona, albumina en cantidad no dosable y pres icia de ácido acetilacético.

Glucemia: $0,42 \%$.

Diagnóstico: Diabetes sacarina. 
En este caso que es en el que mayor glucosuria y mas alta hiperglicemia he podido observar en el Hospital, se obtuvo la desaparición del aź́car al octavo día de tratamiento, después de 4 días de ayuno. Comencé a realimentarla con proteínas. Desgraciadamente no pude seguir la enterma, la que por tener que ausentarse de la capital, abandonó el hospital, cuando recién se comenzaba a incrementar la dieta. A su salida, su estado general era incomparablemente superior al del día de su ingreso, a pesar de haber disminuido dos libras de peso a causa de los varios días de ayno a que estuvo sometida.

\section{CASO Nי 5.}

Hospital de "Santa Ana" Servicio médico del Dr. Monge.

Historia clínica $N^{\circ} 136$.

Sala de "San Miguel". Cama $N^{\circ} 10$.

G. de C., de 70 años, blanca, viuda, peruana, domiciliada en Lima y de ocupación costurera, ingresó al servicio el 12 de marzo de 1923.

Antecedentes hereditarios:

Padre muerto de tifus exantemático. La madre, diabé-. tica, murió a consecuencia de una bronconeumonia, Catorce hijos, seis muertos en la primera infancia, los demás son sanos. 6 abortos.

Antecedentes personales:

Fisiologicos.-Denticion, marcha y vida escolar, normales. Primeras reglas a los 11 años de 4 días de duración. frecue tes desarreglos. 14 partos de termino y 6 abortos, uno de llos con abundante hemorragia. Menopausia a los49 años:- Obesa hasta la edad de 64 años en que comenzó a adelgazar. Fagómana. No hay hábitos alcobólicos. 
Patologicos.-Muy sana en su juventud. Anginas repetidas desde los 25 años; paludismo de corta duración a los 30 años; reumatismo articular agudo. Sarna. A los 46 años sufrió durante varios meses de una dermatosis descamativa que radicó en la palma de las manos y las plantas de los pies. Grippe en agosto de 1922. Constipación cró. nica.

Entermedad actual.-El año 1919 comenzo su enfermedad, habiéndose presentado sucesivamente, y con bastante rapidez los siguientes sintomas: polidipsia, poliuria, prurito vulvar, narcolepsia, astenopia y una excoriación cerca del maleolo externo del pie izquierdo, que no tenía tendencia a la cicatrización. Se preaticó un análisis de orina que reve16 la existencia de glucosa en cantidad de 112 grms. por litro. Fué sometida, por prescripción médica a un régimen, con el que mejoró a los pocos meses. Desde esa época, cada vez que se extralimita en su alimentación se presenta astenia profunda, dolores neuríticos y prurito vulvar. En febrero del año en curso, su estado se agravó; el exámen de orina practicado entonces arrojó la cifra de 100 grms. por litro. En ese estado vino al Consultorio Médico de este mismo hospital, donde se le instituyo un régimen apropiado, pero en vista de que la glucosa persistía, resolvió hospitalizarse.

EXáMEN CĹ́NICO 13 de MaRzo De 1923.

Desarrollo, proporcionado. Actitud indiferente. Piel seca y escamosa; xantodermia palmo-plantar; várices de las piernas. Ulcera varicosa en la piema derecha. Cicatriz en el maleolo izquierdo. Peso 142 libras. Cráneo subdolicocéfalo. Canicie completá. Conjuntivas con pterigión.

Pupilas isocóricas, reaccionan bien. Lengua húmeda con delgada capa de saburra blanquecina. Dientes bien implantados, algunas piezas cariadas. Encías normales. Hipertrofá de la amigdala derecha.

Cuello cilindrico. Cuerpo tiroides impalpable.

No hay particularidades del lado del aparato respirato. rio.

Pulso rebotante y duro, de ritmo regular, late 68 veces al minuto.

Tensión arterial: Mx. 160; Mn. 66; Dif. 94 al Tycos. Retorzamiento del segundo tono abrtico. Arterias esclerosa. 
das, ruedan bajo el dedo; arterias temporales flexuosas. Venas varicosas.

No se palpan ganglios infartados.

Abovedamiento general del vientre. No hay dolorabilidad en ningún sitio del abdómen. Gorgoreo en la fosa iliaca derecha. Hígado y vesícula biliar, normales.

Espacio de Traube, libre. No se palpa bazo.

Función digestiva: A petito conservado; digestiones normales; constipación.

Aparato genito-urinario: Cistocele.

Extremidades: Xantocromia palmo plantar. Ulcera varicosa en la pierna derecha.

Sensibilidad, motilidad y reflejos, normales.

Inteligencia buena. Narcolepsia.

Reacción de Wassermann ligeramente positiva.

En el análisis de orina se comprueba la existencia de glu. cosa en la proporción de $1,25 \%$ y trazas de acetona.

Diagn6stico: Diabetes sacarina.

La enferma, que antes de su ingreso había presentado una glucosuria de $10 \%$, con el régimen que se le instituyó en el consultorio, bajó a $1,25 \%$. A las 48 horas de estadía se obtuvo la aglucosuria, sin haber sido necesario llevarla al ayuno. Permaneció en esas condiciones hasta que se le administró 103 gramos de cárbohidratos en su dieta. Al propio tiempo que se trataba de establecer el bálance de su alimentación, se instituía una medicación antisifilitica.

Se estableció el balance en la siguiente forma: Carbohidratos 92 grms. Proteínas 67 grms. y grasas 134 gramos, con un valor energético de 1800 calorías a proximadamente.

Fue dada de alta el 31 de marzo en muy buenas condiciones. Cada 15 días regresa al servicio para hacerse analizar la orina. El 6 de junio se presentó 1 gramo de glucosa por cien de orina. Fué suficiente con un día de verduras para que desaparesca la glucosuria, que no se ha vuelto a presentar. 


\section{CASO N' 6.}

Hospital de "Santa Ana" Servicio médico del Dr. Monge.

Historia clínica $N^{\circ} 145$.

Sala de "San Miguer". Cama $N^{\circ} 2$.

E. M. de 28 años, blanca, soltera, peruana, domiciliada en la calle de Trujillo, ingresó al servicio el 27 de marzo de 1923.

Antecedentes hereditarios.-Padre muerto de neumonia. La mádre cardiaca, murió anasárquica. 18 hermanos, de los cuales solo viven seis, dos de ellos, enajenados. Un hijo vivo, sano.

Antecedentes personales:

Fisiológicos.-Aparición precoz de la dentinción. Primeras reglas a los 12 años, de 4 dias de duración. Un parto de término. Abusos inmoderados de los alimentos fariná. ceos y azucarados.

Patológicos.-Fué sana basta los 10 años en que tuvo congestión pulmonar, con abundante expectoración sanguinolenta. Paludismo de un año de duración a los 19 años. A la edad de 20 años fue operada por anexitis habiéndosele practicado una histerectomia total. Desde entonces, amenörrea. Después de su operación comenzó a engordar en forma alarmante. Grippe el año 1918. Jaquecas repetidas. Constipación inveterad $\dot{d}$.

Enfermedad actual.--A principios del año en curso, se inicio su enfermedad con sed viva, vértigos y somnolencia. Un mes mas tarde fué presa de prurito vulvar y poliuria, que alcanzaba, en veces, 5 o 6 litros. En ese estado ba contintuado hasta algunas semanas antes de su ingreso al servicio, en que presentó, además de los síntomas antes apuntados, dolores abdominales, astenia profunda y perdida progresiva de la agudeza visual. 
EXÁMEN CLÍNICO 28 DE MARZO DE 1923.

Desarrollo bueno. Abundante panículo adiposó subcutáneo. Numerosos efélides en la cara. Cicatriz operatoria de laparatomía subumbilical.

Cráneo braquicétalo. Cuero cabelludo, normal. Conjuntivas pálidas. Pupilas isocóricas. Vision disminuida. Lengua humeda y limpia. Dientes incompletos, en buen estado de conservación y aseo. Amígdalas normales.

Cuello cilíndrico. No se palpa la tiroides.

Torax normal. Submacicez del vértice del puloón de. recho. Tipo respiratorio costoabrlominal. No hay tos ni expectoración.

Pulso blando y depresible, de ritmo regular. Nada de particular al exámen esteto-acústico del corazón. Arterias y venas normales.

No hay infartos ganglionates.

Abovedamiento general del vientre. No hay puntos dolorosos. Higado, normal; no hay punto cístico.

Espacio de Traube, libre. No se palpa bazo.

Función digestiva: apetito conservado. Digestión lenta. Constipación.

Aparato urinario, sin particularidades.

Aparato locomotor, normal.

Sensibilidad, motilidad y reflejos, normales.

Inteligencia, buena. Narcolepsia.

Reacción de WassermanN, negativa.

Al exámen de la orina se comprueba $9 \%$ de glucosa; acetona en regular cantidad y trazas de albumina.

Glucemia: $0,26 \%$.

Diagnóstico: Diabetes sacarina.

En este caso, se obtuvo la aglucosuria al quinto día de tratamiento y primero de ayuno. Solicitó ser dada de alta, antes de haberse podido establecer el balance de su alimentación. 


\section{CASO $\mathbf{N}^{\circ} 7$.}

Hospital de "Santa Ana" Servicio médico del Dr. Monge.

Historia Clínica $N^{\circ} 147$.

Sala de "San Miguel" Cama $N^{\circ} 21$.

J. T., de 60 años, mestiza, viuda, peruana, vecina de Lima y de oficio cocinera, ingres 6 al servicio el 28 de marzo de 1923.

Antecedentes hereditarios.- Padre muerto "del coraz6n". La madre de reumatismo. Tres hermanos vivos, sanos. 10 hijos, cuatro muertos en su primera infancia; 6 viven; una de sus hijas está alojada en la sala de "La Virgea" de este mismo Hospital por osteo-artritis tuberculosa.

Antecedentes personales:

Fisiologicos.--Menstruación a los 15 años de 4 dias de duración con abundantes pérdidas hemáticas. 10 partos de término, no han habido abortos. Menopausia desde los 49 años. Fagomana.

Hábitos alcobólicos y tabáquicos inmoderados.

Patologicos.-Sarampión, parotiditis y viruela en su in. fanciá. Paludismo a los 36 años, de un año de duráción. Anginas repetidas. Dolores reuma toides desde los 30 años. Gri. pe con bronconeumonia el año 1920. Constipación crónica. Sordera desde muy joven.

Enfermedad actual.-El año 1913, sufrib una caída de 3 metros de altura. Desde entonces sintió pesadez en el periné. Un año más tarde se produjo la caída de la matriz, la que se acompañó de polaquiuria, poliuria y prurito vulvar. La sensación de pesadez en el periné se fué intensificando con el tiempo; sentía dolores vivos, irradiados a los lomos y tras. tornos disuricos. La marcha se hacía penosa por aumentar los dolores. En esas condiciones entró al servicio del Dr. BELlo para bacerse operar. Un análisis de orina practicado en ese servicio, reveló la existencia de glucosa, por lo que fué pasada a nuestra sala. 
EXAMEN CLÍNICO. 29 DE MARZO DE 1923.

Desarrollo proporcionado. Emaciación pronunciada. Piel seca, numerosas vergeturas en el abd 5 men.

Cráneo dolicocéfalo. Conjuntivas subictéricas. Pupilas isocóricas. Visión buena. Lengua hurmeda, con delgada capa de saburra blanquecina. Dientes incompletos y en pésimo estado de aseo. Amigdalas sin particularidaries. Audicion muy imperfecta; la sordera es casi absoluta.

Cuello cilind rico; no se palpa estruma.

Torax aplanado en sentido anteroposterior, excavación de las tosas supra e infraclaviculares. Submacicez y expiración prolongada en los dos vértices pulmonares. Tos seca y escasa expectoración mucosa.

Pulso duro, de ritmo regular, late 90 reces al minuto. Tensión arterial: Mx: 160; Mn: 80; Dif: 80 al Tycos. No hay particularidades en los ruidos del corazón. Arterias flexuo. sas; venas normales. Sistema linfatico: polimicroadenia.

Abdómen aplanado y flácido. Indoloro. Cólon descen. dente ocupado. Higado normal. Nu se palpa la vesicula biliar.

Espacio de Tra UBE, libre. Bazode dimensiones normales.

Función digestiva: Apetito conservado; digestiones normales; constipacion.

A para to génito urinario: Prolapso uterino; cervicitis.

A parato locomotor, normal.

Sensibilidad, motilidad y reflejos, sin particularidades.

Sueño tranquilo.

Reacción de Wassermann, fuertemente positiva. No hay bacilo de KocH en el esputo. 2,7 grms\% de glucosa en la orina.

Diagnóstico: Diábetes sacarina. Sifilis.

Al tercer dia de tratamiento, se obtiene la aglucosuria. Mientras se establece el balance alimenticio, se instituye un tratamiento antisifítico. El 8 de marzo, reaparece el aza. car en la orina, cuando la enferma tomaba 93 grms. de carbohidratos. La enferma, no queriendo someterse a restricciones en su alimentación, abandona el Hospital. Un mes más tarde, regresa nuevamente a ocupar una cama en la sala de "La Virgen", de donde es pasada a la sala de "San Miguel" por glucosuria. Establecido, a proximadamente, el balance de su alimentación, (la enferma constantemente altera el régimen), es pasáda nuevamente a la sala de "La Virgen", donde es operada con toda felicidad el 11 de Junio por.el Dr. Carlos Villaarán. 


\section{CASO $\mathbf{N}^{\circ} 8$}

Hospital de "Santa Ana" Setvicio del Dr. Monge-

Historia clinica $N^{\circ} 148$

Sala de 'San Miguel'. Cama $N^{\circ} 1$

M. de O., de 49 años, blanca, ćasada, peruana y domi. ciliada en la calle de "Rufas", ingresó al servicio el 31 de marzo de 1923.

Antecedentes herefitarios.-Padre muerto de hemorragia cerebral. La madre fallecio de neumonia. 17 hermanos, de los cuales 13 murieron en su primera infancia, 4 vivos, y sanos. Dos hijos muertos a los pocos meses de nacidos y dos abortos.

\section{Antecedentes personales:}

Fisiológicos.--Primeras reglas a $\operatorname{los} 13$ años, de tres. días de duración, no ha tenido desarreglos. Dos partos de término y dos abortos. Menopansia desde bace dos años. Malos hábitos alimenticios.

Patologicos.--Sarampión, coqueluche y paludismo pernicioso en su infancia. Reumatismo articularen varias oportunidades. Faringitis y amigdalitis repetidas veces.

Enfermedad actual.--En el mes de setiembre del año pasado, comenzó su entermedad con polidipsia y angustia epigástrica. Al mes siguiente se presentó poliuria abundante,. que la enferma atribuía a la gran cantidad de líquidos que bebía. Al mismo tiempo, se adelgazaba notablemente. Por indicación médica, se le practicó un análisis de orina en el mes de enero del año en curso, habiéndose comprobado en ella la existencia de glucosa en fuerte proporción $(11,2 \%)$. No obstante el tratamiento dietético y medicamentoso que se le instituyó, su mal hacía progresos. Uitimamente se quejaba de dolores diseminados por todo el cuerpo, astenia pro funda y pérdida de la agudeza visual. 


\section{EXAMEN CLÍNICO $1^{\circ}$ DE ABRIL DE 1913}

Desarrollo proporcionado. Emaciación moderada. Piel sudorosa con numerosos nevus pigmentarios. Cicatriz en la cresta tibial izquierda.

Cráneo braquicéfalo. Cuero cabelludo normal. Pupilas iguales. Conjuntivas pálidas. Visión disminuida. Lengua seca y resquebrajada. Dientes incompletos. Piorrea alveolar. Amígdalas hipertrofiadas.

Cuello cilindrico. No se palpa la tiroides.

Torax globuloso. Lijera condensación de los vértices pulmonares. Signos de enfisema en las bases. No hay tos ni expecturación. Tipo respiratorio, costal superior.

Pulso blando, de ritmo regular, late 68 veces al minuto. Cnrazón sin particularidades. Arterias elásticas. Venas normales.

No hay infartos ganglionares.

Abdomen depresible, indoloro. Hígado basculado. No hay punto cístico.

Función digestiva: Ligera anorexia. Digestión y defecación normales.

Nada digno de anotarse del lado del aparato génito uri. nario.

Apara to locomotor, normal.

Sensibilidad, motilidad y reflejos, conservados.

Sueño tranquilo.

Reacción de Wassermann, negativa. Cutireacción de Von Prrguet, negativa. 9,5 grms\% de glucosa en la orina.

Diágnóstico: Diabetes sacarina.

Al septimo día de tratamiento, la enferma abandonó el Hospital. 


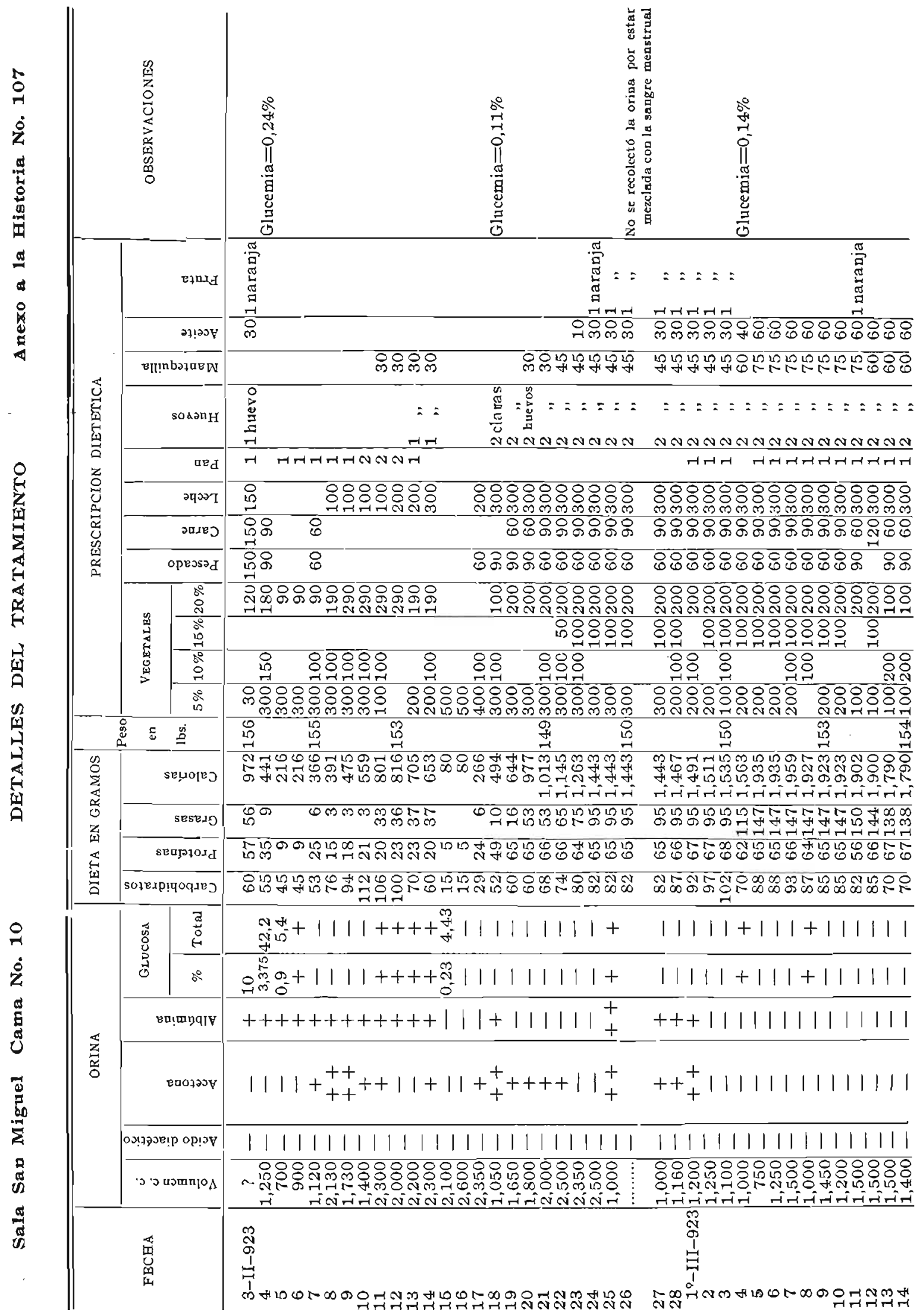




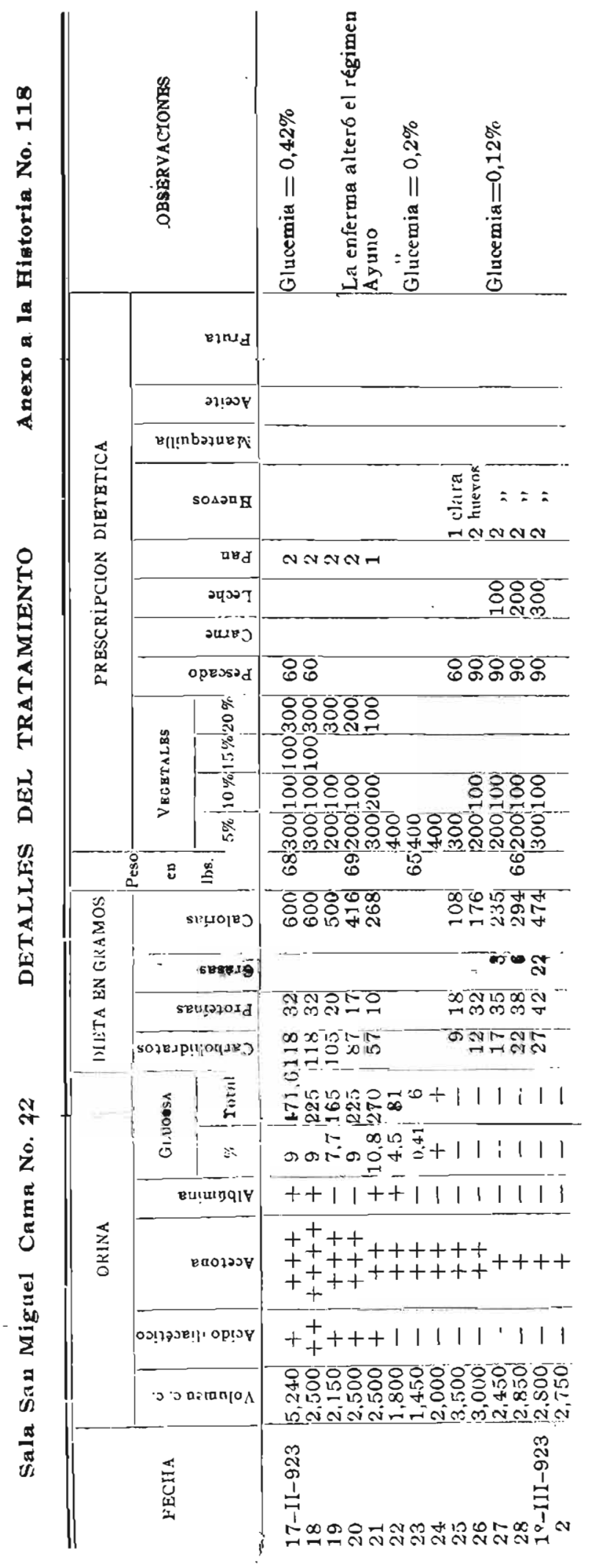




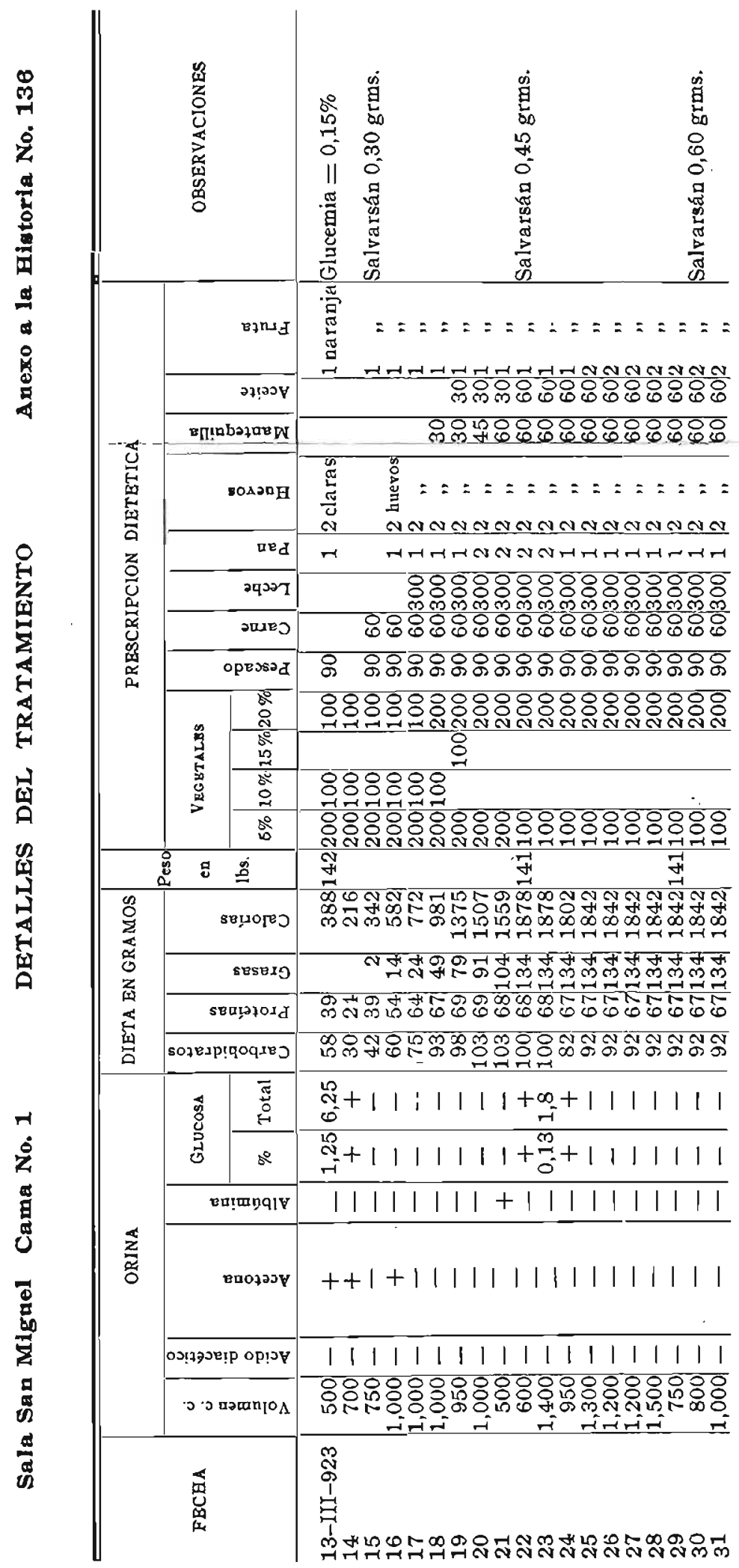




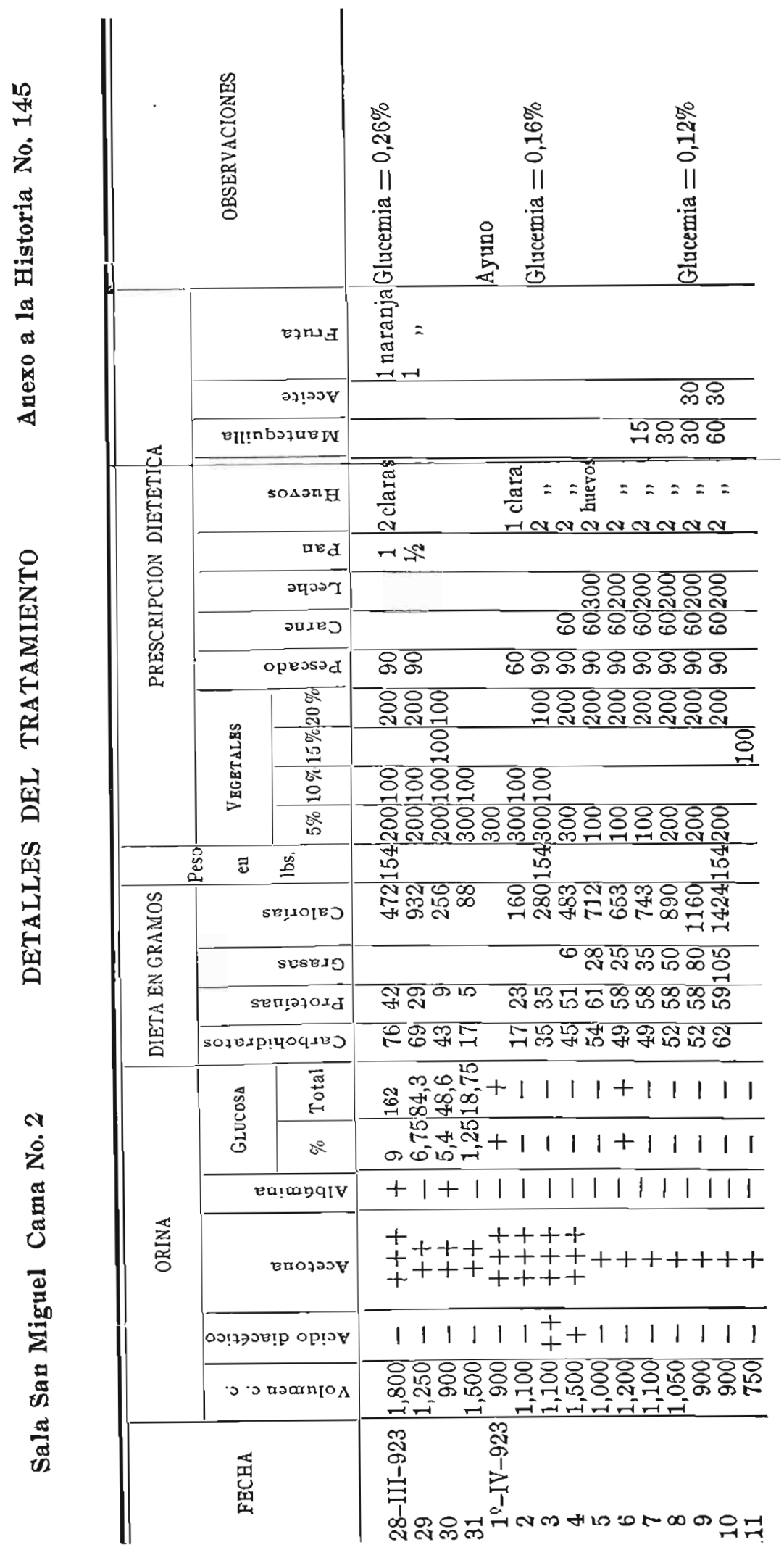




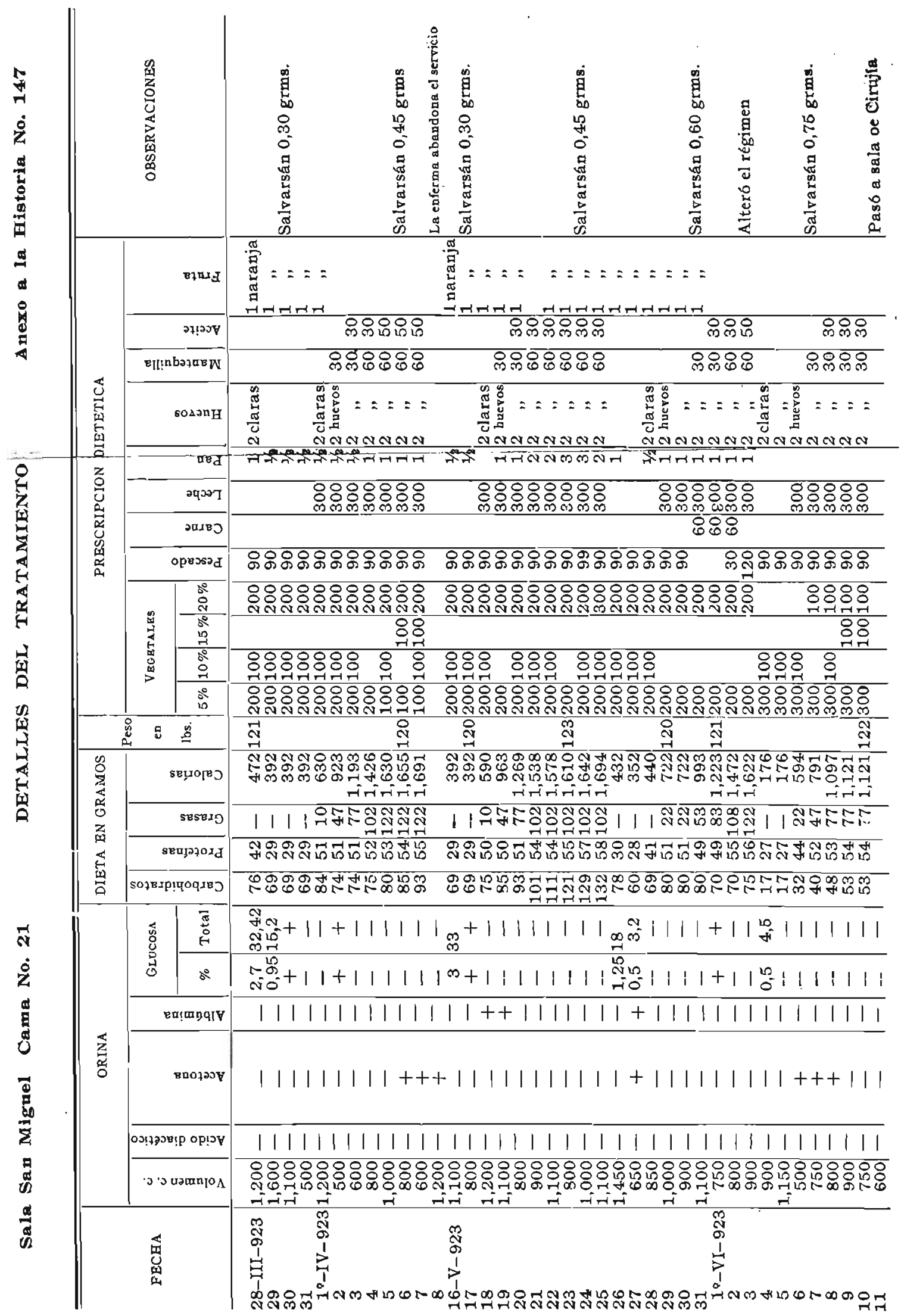



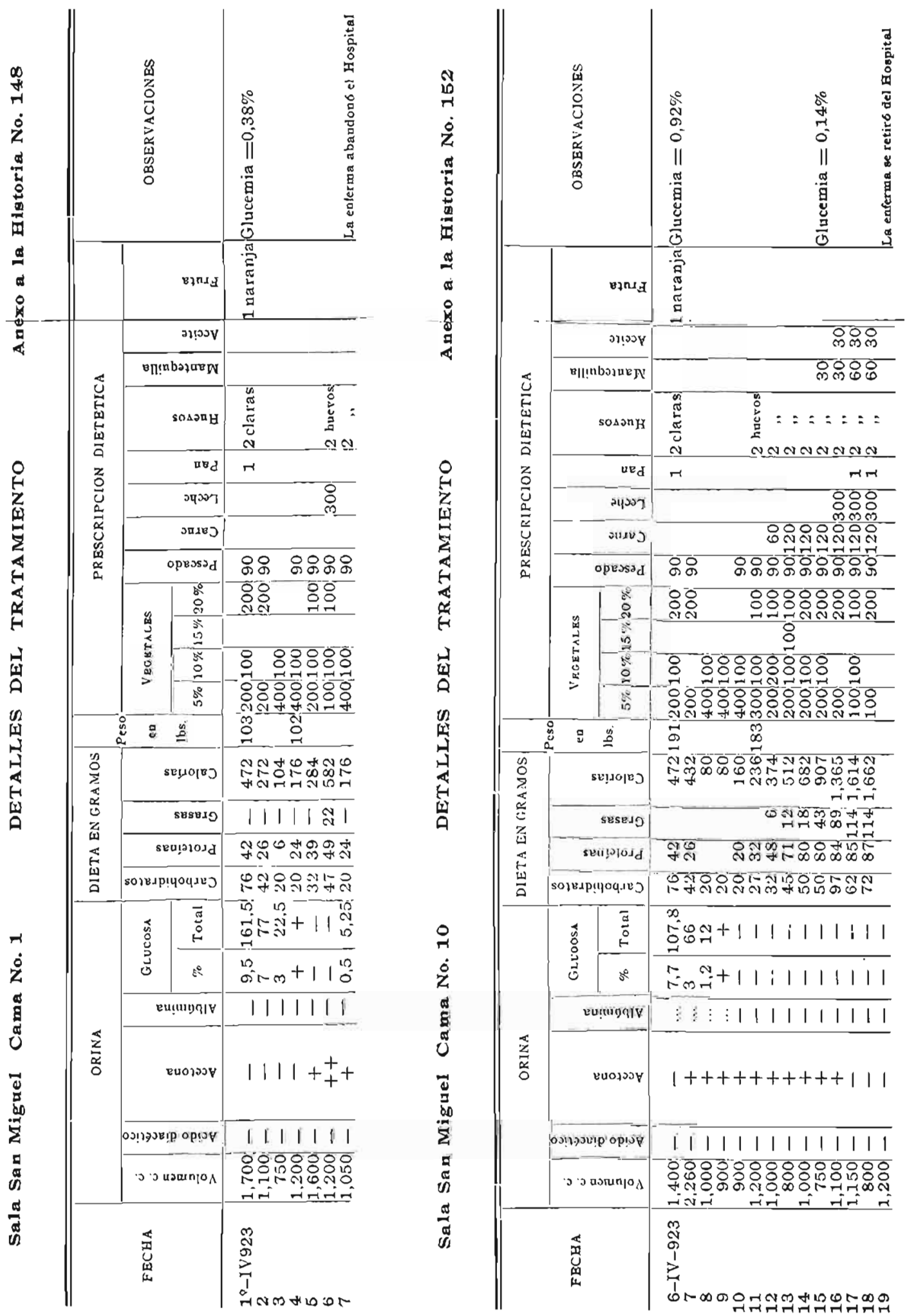


\section{Caso $\mathbf{N}^{\circ} 9$.}

Hospital de "Santa Ana". Servicio médico del Dr. Monge.

Historia Clinica $N^{\circ} 152$.

Sala de "Sán Miguel" Cama No 10.

O. V., mestiza, de 40 años, castda, peruana, domiciliada en Barranco y de ofcio cocinera, ingresó al servicio el 5 de abril de 1923.

Antecedentes hereditarios.-Padre vivo, sano. La madre murió de parto. Un hermano vivo, sano. Cuatio hermanos muertos: dos de tuberculosis y dos de bronconeumonia. Tres hijos vivos, sanos. Cuatro muertos a los pocos dias de nacidos. Tres abortos.

Antecedentes personales:

Fisiologicos.--Primeras reglas a los 14 años, de 4 días de duración, con abundantes pérdidas sanguínéas. Siete partos de término y tres abortos. Obesa desde los 21 años. Malos hábitos alimenticios.

Patolbgicos.-Solo recuerda haber padecido de cólicos hepáticos desde la edad de 33 años. Menorragias desde el mes de noviembre.

Enfermedad actual.-En marzo del año pasado comenzo su entermedad con polidipsia, poliuria, astenia y pérdida de la agudeza visual. Un análisis de orina revelo la existencia de treinta y tantos gramos de glucosa. Ultimamente, se presentan sensaciones de quemadura en las extremidades, dolores lumbares, insomnio y alucinaciones visuales.

\section{EXAMEN CLINICO.}

Desarrollo exuberante. Abundante paniculo adiposo. Intértrigo inguinal y submamario.

Cráneo braquicéfalo. Cuero cabelludo normal. Conjuntivas ictéricas. Pupilas iguales. Vision disminuída. Lengua 
secá. Dientes en pésimo estado de conservación; casi todas las piezás están cariadas. Amígdalas normales.

Torax bien conformado. Pulmones sin particularidades.

Pulso blando y depresible, de ritmo regular. No hay particularidades en el corazón. Arterias elásticas. Venas normales.

No se palpan ganglios.

Abdómen abovedado y depresible; gorgoreo en la fosa iliaca derecha.

Higado normal. Dolorabilidad en el punto cístico y en la zona pancreático-coledocianá.

Aparato génito urinario, normal.

Aparato locomotor, sin particularidades.

Sensibilidad, motilidad y reflejos, normales.

Reacción de WasSERMANN, negativa.

7,7 gramos de glucosa por ciento y trazas de albúmina en la orina.

Diagnóstico: Diabletes sácarina.

Se obtuvo la aglucosuria al $5^{\circ}$ día de tratamiento. La enferma abandonó el hospital, antes de establecerse el balance de su alimentación; habiendo podido tolerar, sin que aparezca glucosuria, hasta 72 gramos de hidrocarbonados.

\section{Bibliografía}

1.-Allen. The Journal of the American Meclical Asosiation Vol 3 N9 6 .

2.-Allen, Mitchel y James. The J, of the A. M. A. Vol. $4 \mathrm{~N}^{\circ} 5$.

3.-Arthus Maurice.-Precis de Chimie Phsiologique.

4.--Aguilar Meza.--Las autointoxicaciones endocrinas como causa de la diabetes sacarina.

5.--Boas.--Regímenes alimenticios.

6.--Buchard.--Retardo de la nutrición.

7.-Brouardel et Gilbert.-Nouveau Traité de Medecine. Vol XII.

8.-Bezangon, Labbe, Bernard et Sicard.-Pathologie Medical. Vol V.

9.-Calic $6 \mathrm{~J}$ de.-Regimenes alimenticios.

10.-Castaigne et Rathery.-Le livre du Medecin. Vol XVI.

11.-Dieulafoy.-Manuel de Pathologie Interne. Vol IV.

12.-Ebstein W.-Medicina clínica y Terapeutica. Vol VI.

13.-Guelpa.-Autointoxication et desintoxication.

14.- Gilbert et Fournier.-Pathologie Interne.

15.- Grasset.--Fisiopatología Clínica

16.- " Terapéutica

17.-Hewlett.-Monographic Medicine. Vol V. 
18.--Holmes...Journal of the A. M. A. Vol 7. $\mathrm{N}^{\circ} 3$.

19.---Joslin Eliot P.---The treament of Diabetes Mellitus.

20.-- " , , A Diabetic Manual, .

21.- " " " " Tine Journal ot the A. M. A. Vol 7. No 12.

22.--Landouzy et Bernard.-.-Elements d' Anatomie et Phisiologie $\mathrm{Me}^{-}$ dicales.

23.---Lambling.--Precis de Biochimie.

24.--Labbe Marcel- Le diabéte sucré.

25.-- " ", Clinique et laboratoire 'Año II. No 1. )

26.---Lepine.---Lediabcte et son Traitment.

27.-Macleod.-Phisiology and Biochemistry in Modern Medicine.

28.-Martinet A.-Therapeutique Clinique.

29.-Manrique Belisario. --Prograna de Terapéutica y Materia Médica.

30.-Monge M. Carlos.-Gaceta Medica Peruana. año I No 3.

31.- Novoa Santos.-Tratamiento de la diabetes Mellitus.

32.-Newburg. - The Medical Clinics of North America. Vol 6. No 5.

33.-Newburg and Marsh.-Archives of Internal Medecine. Dic. 1920.

34. -Odriozola Ernesto.- Anales de la Facultad de Medicina de Lima. Año IV. No 20.

35.- " " Lecciones clinicas.-Diabetes. (Prima de la Gaceta de los Hospitales).

36.-Pinard Marcel-_La-Medecine--Nov. 1922.

37.-Roger Widal et Te!ssier.-Nouveau Traite de Medecine. Fas. VII.

38. -Rathery-La cure de Bouchardat et le Traitement su diabetico sucre.

39.-Robin A.-Traite de Therapeutique Pratique. Vol III.

40.--Roger. - La Presse Medicale.-Nं 92.-Nor. 1922.

41.- Strouse.-The Journal of the A. M. A. Vol 4. No 4 .

42.- Sergent, R. Dumas et Babnneix.-Traite de Pathologie Medicale et Therapeutique applique. Vol. XXIII.

43.-Von Noorden La diabetes sacarina y su tratamiento. 